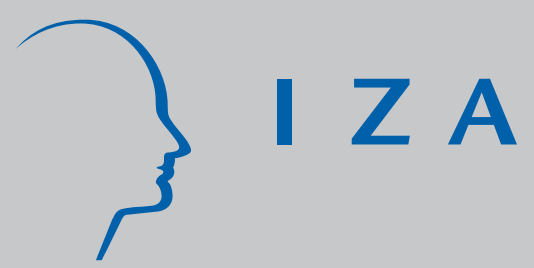

IZA DP No. 269

Re-employment Dynamics of Disabled Workers

Hielke Buddelmeyer

March 2001 


\title{
Re-employment Dynamics of Disabled Workers
}

\author{
Hielke Buddelmeyer \\ IZA, Bonn \\ Discussion Paper No. 269 \\ March 2001 \\ IZA \\ P.O. Box 7240 \\ D-53072 Bonn \\ Germany \\ Tel.: +49-228-3894-0 \\ Fax: +49-228-3894-210 \\ Email: iza@iza.org
}

This Discussion Paper is issued within the framework of IZA's research area The Welfare State and Labor Markets. Any opinions expressed here are those of the author(s) and not those of the institute. Research disseminated by IZA may include views on policy, but the institute itself takes no institutional policy positions.

The Institute for the Study of Labor (IZA) in Bonn is a local and virtual international research center and a place of communication between science, politics and business. IZA is an independent, nonprofit limited liability company (Gesellschaft mit beschränkter Haftung) supported by the Deutsche Post AG. The center is associated with the University of Bonn and offers a stimulating research environment through its research networks, research support, and visitors and doctoral programs. IZA engages in (i) original and internationally competitive research in all fields of labor economics, (ii) development of policy concepts, and (iii) dissemination of research results and concepts to the interested public. The current research program deals with (1) mobility and flexibility of labor markets, (2) internationalization of labor markets and European integration, (3) the welfare state and labor markets, (4) labor markets in transition, (5) the future of work, (6) project evaluation and (7) general labor economics.

IZA Discussion Papers often represent preliminary work and are circulated to encourage discussion. Citation of such a paper should account for its provisional character. 
IZA Discussion Paper No. 269

March 2001

\section{ABSTRACT \\ Re-employment Dynamics of Disabled Workers*}

We investigate the duration of time until the first work resumption for a cohort of people who receive disability insurance benefits. One of the peculiarities of the disability insurance program under investigation is that the level of benefits not only depends on previous wages, but also declines over time according to a schedule based on age, the amount of work experience, and the level of disability. As a result, different people will face different benefit schedules and hence are likely to make different choices regarding a return to work. To fully absorb the structural aspect of the disability program, we specify and estimate a behavioral labor supply model where individuals receive job offers that they can accept or decline. Possible reforms of the disability program are evaluated, including ending the disability program altogether.

JEL Classification: J22, J64, C41

Keywords: Disability, labour supply, behavioural modeling

Hielke Buddelmeyer

P.O. Box 7240

D-53072 Bonn

Germany

Tel.: +492283894522

Fax: +492283894510

Email: buddelmeyer@iza.org

\footnotetext{
*Acknowledgements: I would like to thank C. Flinn and W. Vanderklaauw for very useful comments and suggestions.
} 


\section{Introduction}

The disability program under investigation is one of many programs that comprise the Dutch social security system but it is an important one. It's an important program in itself because of the sheer number of people enrolled. When the program was initiated in 1967 , only $6 \%$ of the labor force was registered disabled. This is comparable with countries such as Sweden and Germany, yet already about double the rate for the United States. During the seventies, enrollment increased across most countries but unlike the way it did in the Netherlands.

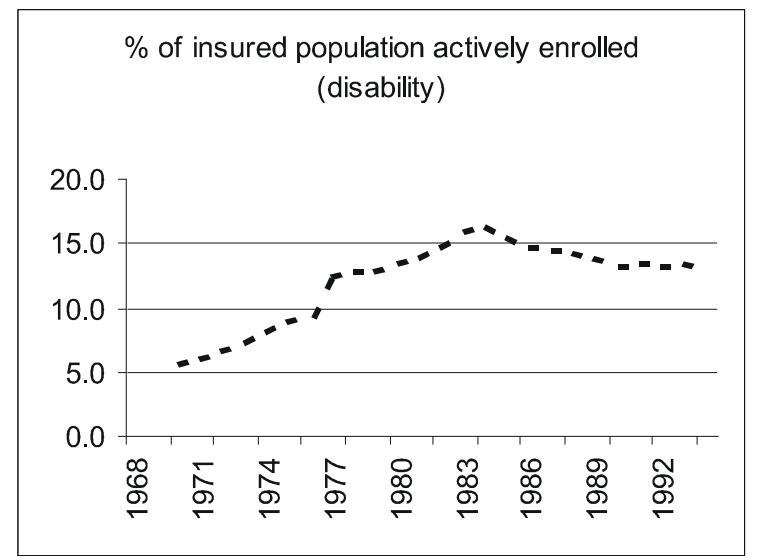

Figure 1. Enrollment in the disability program

The program was particularly popular among the older people in the labor force. By the end of the decade there were almost as many people ages 60 to 64 working as there were people receiving disability benefits. For people between the ages of 45 and 59, this ratio had climbed to one in four and for workers under 45 it was still about one in twenty (in both cases an increase of about $250 \%$ over the course of 10 years). Overall, enrollment peaked at about $16 \%$ in the mid eighties but has since declined and stabilized from 1994 onwards at about $13 \%$ (figure 1). This implies that overall about one in eight workers is registered disabled. It is important to note that disability in the Dutch disability program is defined purely as a loss in income capacity and does not correspond one-to-one with the everyday meaning of the word disabled. However, they are closely related. Yet, given the notion that disability is purely defined as a loss in earning capacity, the $13 \%$ enrollment rate gives rise to the generally perceived notion that a large share of that $13 \%$ (if not the majority) should really be regarded as hidden unemployment. During the period under study, the disability program in the Netherlands was administered by employer and employee organizations also known as the 'social partners'. Both parties in this case had an incentive to divert superfluous workers into the disability program since that program had a more generous benefit structure then the regular unemployment program. Hassink et. al. (1997) concluded that by the 
end of the eighties, about $10 \%$ of the observed inflow into disability were in fact dismissals. De Mooij (1999) estimates that as much as $50 \%$ of disability benefits is due to improper use. Not only was the disability program (mis)used as a place to dump redundant workers, but it also provided an incentive for employees to retire, especially when these employees reached near retirement age. Although it is difficult to say which part of the decline in labor force participation rates of older workers is due to incentives provided by the disability program, empirical research suggests that the main explanation for the sharp drop in labor force participation among the elderly stem from exactly those incentives as provided by the disability program and other private and public schemes (Kapteyn and de Vos, 1997 and Kerkhofs et. al., 1999). A contributing factor to the observed increase in disability enrolment over time is the increase during that same time span in the number of people looking for employment, pushing out older, less able workers. A phenomena also present during times of recessions. Adding fuel to this process was a continuing relaxing of the eligibility criteria. One could even argue that cultural changes that took place in the sixties ultimately affected peoples' attitude towards public assistance and work and hence contributed to the increase in enrollment through a reduced sense of 'duty'. The US were quick to realize that the rapid increase in the rolls required action and, in the late seventies, tightened eligibility. Also Germany tightened eligibility standards albeit a bit later, during the mid eighties. The Netherlands substantially revised the social security system, including the disability program, in 1987 and 1993. Both these revisions will be discussed in more detail later. Table 1 shows the number of disability transfer recipients by age and country for the period 1970 through 1994. Comparing the age group 60 to 64 supports the finding that the disability program in the Netherlands provides a strong incentive for early retirement. Another noticeable fact is that Germany has significantly fewer incidences of disability for younger workers than do the other countries. 


\begin{tabular}{|c|c|c|c|c|c|c|}
\hline & \multicolumn{6}{|c|}{$\begin{array}{l}\text { Disability transfer recipients per } 1,000 \\
\text { active labor force participants (by age) }\end{array}$} \\
\hline & 1970 & 1975 & 1980 & 1985 & 1990 & 1994 \\
\hline 15 to 44 years & & & & & & \\
\hline The Netherlands & 17 & 32 & 57 & 58 & 62 & 66 \\
\hline United States & 11 & 17 & 16 & 20 & 23 & 38 \\
\hline United Kingdom & 8 & 9 & 11 & 20 & 23 & \\
\hline Germany $^{1}$ & 7 & 6 & 7 & 8 & 5 & 5 \\
\hline Sweden & 18 & 20 & 19 & 20 & 21 & 27 \\
\hline \multicolumn{7}{|l|}{45 to 59 years } \\
\hline The Netherlands & 113 & 179 & 294 & 305 & 339 & 289 \\
\hline United States & 33 & 68 & 83 & 71 & 72 & 96 \\
\hline United Kingdom & 48 & 46 & 51 & 97 & 119 & \\
\hline Germany $^{1}$ & 75 & 64 & 84 & 103 & 75 & 80 \\
\hline Sweden & 66 & 95 & 99 & 108 & 116 & 143 \\
\hline \multicolumn{7}{|l|}{60 to 64 years } \\
\hline The Netherlands & 299 & 437 & 1033 & 1283 & 1987 & 1911 \\
\hline United States & 154 & 265 & 285 & 254 & 250 & 294 \\
\hline United Kingdom & 219 & 195 & 209 & 357 & 413 & \\
\hline Germany $^{1}$ & 419 & 688 & 1348 & 1291 & 1109 & 1064 \\
\hline Sweden & 229 & 382 & 382 & 512 & 577 & 658 \\
\hline \multicolumn{7}{|l|}{ Total population 15 to 64 years } \\
\hline The Netherlands & 55 & 84 & 138 & 142 & 152 & 151 \\
\hline United States & 27 & 42 & 41 & 41 & 43 & 62 \\
\hline United Kingdom & 29 & 28 & 31 & 56 & 68 & \\
\hline Germany ${ }^{1}$ & 51 & 54 & 59 & 72 & 55 & 54 \\
\hline Sweden & 49 & 67 & 68 & 74 & 78 & 97 \\
\hline
\end{tabular}

Table 1. Disability transfer recipients per 1,000 active labor force participants. Source: Aarts et. al. (1996), pages 4 and 5.

Starting in the eighties, social security reform -especially the disability programbecame a popular topic of political debate because the number of people enrolled just seemed to have exploded. The fact that the explosive growth was endemic to the Netherlands only intensified the debate. Even after reforms, the benefits in the Dutch disability program are still relatively generous, especially compared to the two major programs in the US, the Social Security Administration's Disability Insurance (SSDI) and Supplemental Security Income (SSI). The benefit schedule in the Dutch disability program has some very interesting features which are the result of the fact that benefits are comprised of disability bene-

\footnotetext{
${ }^{1}$ German data refer to the former Federal Republic
} 
fits on the one hand and unemployment benefits on the other. Providing the level of disability does not change, these disability benefits remain constant over time. The unemployment benefits however do decline over time. The way these unemployment benefits decline over time depends on individual characteristics such as work experience and age. As a result, different people face different benefit schedules not only because they have different levels of disability but also because they have different individual characteristics. This will lead them to make different choices with regards to returning to work. The role of benefits in the re-employment decision is our main topic of investigation. The effect of disability transfers on labor supply in the US has been studied before (Parsons 1980 and Haveman et. al. 1991). Aarts and de Jong (1992, 1996) and Gelauff and Graafland (1994) have analyzed disability and the effect of changes in the benefit structure for the Netherlands in particular. The setup here is different in terms of modeling. To analyze the effect of (declining) benefits on the decision to resume work, we specify a labor supply model with forward looking individuals who maximize their lifetime utility. This approach will allow us to analyze what would happen if we were to make changes in the benefit schedule, including ending the disability program altogether and transferring the recipients to the unemployment program. A closer look at the data is provided in section 3. Section 2 gives a more detailed description of the disability program and section 4 describes the model. The results of the estimations are discussed in section 5 . In section 6 we analyze the effects of a series of proposed changes to the disability program. Finally, section 7 will contain our final conclusions. 


\section{The disability program and its connection to unemployment}

There is a distinction between welfare programs and insurance programs, which together, comprise the social welfare system in the Netherlands ${ }^{2}$. The primary objective of the disability program, an insurance type program, is to protect people's standard of living when disability results in an income loss. Another important motivation for the program is to keep disabled workers part of the work force. This is reflected by measuring disability as a percentage rather that an all or nothing condition. The welfare and insurance type of programs not only differ in their underlying philosophy, they also differ in their financing. The insurance programs are financed by a pay as you go system through mandatory premiums paid by employers, employees or both, whereas the welfare programs are financed by general (tax) revenues. The programs also differ in a third way, the way they are administered. The insurance programs are administered by independent agencies governed by unions and employer organizations. The welfare programs are, in contrast, administered by local governments. When the disability program was introduced in 1967, it replaced a collection of industry specific measures that had been introduced in the first half of the twentieth century. The Industrial Accident Act of 1903, the predecessor of the 1967 disability program, only covered certain professions and only particular types of accidents. Over time, coverage expanded both in the types of risks that were covered, as well as the type of workers that were covered. The current disability program is tightly connected with the sickness program and the unemployment program. The sickness program is the first program that applies when an employee suffers a loss in income due to illness, injury or pregnancy. Until 1985, sickness benefits replaced 80 percent of the gross wage earnings, but the replacement rate has since been reduced to 70 percent. However, in nearly all cases, the employer supplements the benefits to $100 \%$ of the net earnings as agreed by unions and employer organizations in collective bargaining agreements. After a revision in 1994, the sickness benefits paid to the employee during the first 6 weeks of sick leave are paid by the employer. The benefits are still a mandatory minimum of $70 \%$ of the gross wage earnings and the employer may cover this risk by buying insurance in the private market. The sickness benefits run out after one year, at which point one becomes eligible for the disability program. The sickness program can thus be regarded as a waiting period for the disability program. The difference between the sickness and the disability program is that the sickness program covers income loss due to not being able to do one's own job, while the disability program covers income loss due to not being able to do work that is commensurate with one's own job. Disabled is defined in Dutch law as

a person who, as a consequence of illness or injury, is fully or partly unable to earn - in employment commensurate to one's strength,

\footnotetext{
${ }^{2}$ See Spijkerboer, P.M. and van der Zee, H (1996) for a detailed overview and history of all social insurance programs in the Netherlands.
} 
capabilities, training and work history - what physically and mentally healthy persons in otherwise similar circumstances usually earn (Emanuel et al., 1984).

The definition has been changed after the revisions of 1993/94 to include all jobs that one could still do given one's physical and mental limitations.

\subsection{Determining the level of disability}

Upon entering the disability program, after the one year period of sick leave has been completed, the worker will receive two interviews. The first interview is with a medical professional who determines the health profile of the worker as well as the presence of any physical and/or mental limitations. The second interview is with a labor market professional who, on the basis of this profile, determines what jobs the worker potentially could still do and hence what the worker's remaining potential earning capacity is. The disability level is then defined as

$$
\frac{A E-E C}{A E} * 100=\% \text { disabled }
$$

where $\mathrm{AE}$ are the average earnings the individual would receive in the job(s) previously held if he were not disabled. EC is the estimated remaining earning capacity, or the income from work a person would be able to earn with commensurate employment. The complement of the percentage disabled is the percentage unemployed. The remaining potential earning capacity is determined with the help of a job database of $8,000+$ existing jobs with detailed job descriptions $^{3}$. The concept of disability and the risk covered by the program is different in the Netherlands from that of other countries. The cause of the income loss is of no relevance, i.e. it does not have to be due to an on the job incidence. For example, a telephone operator who becomes paralyzed from the waist down but is still fully capable (after perhaps some small alterations to the work space) of operating the telephone will be considered not disabled because there is no loss in earning capacity. On the other hand, a neural surgeon with a very light form of Parkinson's disease is considered fully disabled, even though he could still become a university professor. After the level of disability is determined, one is classified into one of eight brackets ranging from not disabled (15\% or less

\footnotetext{
${ }^{3}$ Before the revisions of 1993 , the labor market professional searched this database for jobs that complied with the applicant's medical profile, level of education, previous job level and geographic region. The geographic region was then expanded until five or more jobs were found or the region spanned the entire country. Each job had to represent at least 10 positions. The remaining earning capacity was set equal to the median wage of the jobs found. After the reforms of 1993, the remaining earning capacity was computed by taking the median income of the 3 best paying jobs found in the database, nation wide, representing at least 30 positions combined, resulting in a sharp increase in the remaining earning capacity and hence a substantial decrease in the level of disability. The labor market and medical professional make the final decision. The computer serves as a tool, albeit a powerful one.
} 
disabled) to fully disabled ( $80 \%$ or more disabled). Not disabled in this case means that the person is viewed and treated as regularly unemployed. Each of the eight disability brackets then corresponds to a situation in which total benefits consist of a share $\alpha$ of the disability benefits a person would be receiving if he was fully disabled plus a share of 1- $\alpha$ of the unemployment benefits this person would be receiving if he was regularly unemployed. Table 2 lists these different $\alpha$ for each of the eight disability brackets.

\begin{tabular}{l|c|c|}
$\%$ disabled & $\begin{array}{c}\text { disability share } \\
\text { in benefits }(\alpha)\end{array}$ & $\begin{array}{l}\text { unemployment share } \\
\text { in benefits }(1-\alpha)\end{array}$ \\
\hline$[0,15)$ & 0 & 1 \\
{$[15,25)$} & 0.2 & 0.8 \\
{$[25,35)$} & 0.3 & 0.7 \\
{$[35,45)$} & 0.4 & 0.6 \\
{$[45,55)$} & 0.5 & 0.5 \\
{$[55,65)$} & 0.6 & 0.4 \\
{$[65,80)$} & 0.725 & 0.275 \\
{$[80,100)$} & 1 & 0 \\
\hline
\end{tabular}

Table 2. Shares of the disability benefits in total benefits for different disability levels.

\subsection{A short history of the disability program}

The 1987 changes to the social welfare system sought to stop and undo the persistently strong growth of these programs, in particular the disability program. Until 1987 the law acknowledged the difference between theoretical and actual (market) remaining earning capacity. It was argued that disabled workers could face potential discrimination by employers, resulting in very small probabilities of finding employment. The law therefore asked for the labor market conditions to be taken into account, meaning an assessment had to be made about the likelihood a disabled person was to find actual commensurate employment. This task proved to be a highly subjective task and in practice it was assumed that difficulties in finding employment was due to discrimination by employers. As a result, all disability applicants who were in principle only partially disabled, where treated as fully disabled. In 1986, one year prior to the restructuring of $1987,88 \%$ of all disability assessments resulted in full disability. The 1987 restructuring eliminated the inclusion of labor market conditions in the assessment of disability. Disability benefits were now only administered based on the theoretical assessment of remaining earning capacity, regardless of the chances of actually being able to obtain such employment. Benefits depend on the level of disability and consist of a fraction of the previous earnings (or a maximum). Table 3 shows these replacement rates over time 


\begin{tabular}{l|l|l|l|}
\multirow{2}{*}{ \% disabled } & \multicolumn{3}{|l}{ Replacement Rates } \\
\cline { 2 - 4 } & July 67 & Jan 85 & $>$ Jan 87 \\
\hline $0-15$ & 0 & 0 & 0 \\
$15-25$ & 10 & 9.5 & 14 \\
$25-35$ & 20 & 17.5 & 21 \\
$35-45$ & 30 & 26.5 & 28 \\
$45-55$ & 40 & 35.5 & 35 \\
$55-65$ & 50 & 44.5 & 42 \\
$65-80$ & 65 & 57.5 & 50.75 \\
$80-100$ & 80 & 70.5 & 70 \\
\hline
\end{tabular}

Table 3. Replacement rates over time in the disability program.

In August of 1993 another major revision of the disability program was introduced since the decrease in the rolls that followed the 1987 reform had been more than offset. The notion of commensurate employment was no longer defined by educational attainment, work history or vocation, but instead applied to all employment the disabled worker was still capable of performing, given his experience, education and physical and/or mental limitations. The second important change that brought the program more in line with international standards was that the limitations causing the disability had to be objectively assessable. The search criteria used to compute the remaining earning capacity with the help of the job database also changed. Before the reforms of 1993, the remaining earning capacity was computed as the median income of at least 5 jobs found in the database, each representing at least 10 positions, starting in one's own region. After the reforms of 1993, the remaining earning capacity was computed by taking the median income of the 3 best paying jobs found in the database, nation wide, representing at least 30 positions combined. The third important change was that the notion that disability benefits were awarded indefinitely (up to age 65) independent of work experience was also eliminated. After 1993, benefits were awarded for a maximum of 5 years, followed by a reassessment determining disability status. Similar to the unemployment program that has an earnings related benefit with a work experience dependent duration, the disability program now awards earnings related benefits identical to the benefits paid under the old disability program for a limited duration that depends on age, as a proxy for work experience. After these benefits run out one receives $70 \%$ of the gross minimum wage and an age dependent supplement.

\subsection{A short history of the unemployment program}

Today's unemployment program was created in July of 1952 and restructured in January 1987. Prior to 1952 employers and employees paid premiums to maintain an industry specific fund. The government subsidized these industry or employer specific funds. Their role was to provide replacement income for temporarily laid off workers. Employees and employers also paid premiums to provide replacement income for permanently laid off workers. The unemployment program of 1952 built on these two pillars, the provision for temporarily 
laid off workers that was industry specific and the universal national provision for permanently laid off workers. With the introduction of the Unemployment Act of 1952 the latter provision was now financed by premiums paid to the federal government by both employees and employers. In the event of unemployment one would first receive the industry specific income replacement paid out by the industry specific funds. Duration differed by industry but lasted at least a mandatory 48 days. Replacement rates also varied between 60 and 80 $\%$ depending on household composition. After these industry specific benefits had run out one would receive benefits provided by the federal government of an equal amount. In 1967 the maximum unemployment duration was fixed at 130 days, of which the first 40 days were the industry provided benefits and the following 90 days the government provided benefits. The replacement rate was also fixed at $80 \%$. In 1985 this replacement rate was reduced to $70 \%$ and has remained at that level ever since. In January of 1987 the unemployment program was fully redesigned. For the first time unemployment was explicitly defined in the law. A person is considered unemployed if he lost at least 5, or half the number of usual work hours per week and he is available to accept employment. Availability is not defined in the law but leaves room for benefit penalties or even cancelation of benefits in case an individual remains unemployed due to their own actions, such as refusing work. Another change that was made in January of 1987 was that the industry provided benefits disappeared, i.e. all benefits are now government provided. It is also the government who collects all the premiums paid by employees and employers. One is eligible for unemployment benefits if one has worked 26 out of the 52 weeks prior to unemployment. Benefits consist of $70 \%$ of previous earnings (with a maximum) and duration is 6 months. If one has worked 3 or more years in the 5 year prior to unemployment, for a minimum of 8 hours a week, one is eligible for an extension. The duration of this extension depends on work experience (Table $4)$.

\begin{tabular}{c|c|} 
work experience (years) & $\begin{array}{c}\text { extension of duration of high (first stage) } \\
\text { unemployment benefits (months) }\end{array}$ \\
\hline less then 5 & 0 \\
5 or more & 3 \\
10 or more & 6 \\
15 or more & 12 \\
20 or more & 18 \\
25 or more & 24 \\
30 or more & 30 \\
35 or more & 42 \\
40 or more & 54 \\
\hline
\end{tabular}

Table 4. Extension of earnings related unemployment benefits.

After these wage related benefits run out, one is eligible or non means tested benefits of $70 \%$ of the minimum wage. Duration is one year, unless one was 
older than $57 \frac{1}{2}$ at the onset of unemployment. In that case duration of these non means tested benefits is $3 \frac{1}{2}$ years. After this period the benefits become means tested at the household level. In 1995 the eligibility criteria were further tightened. One now needs to have worked 26 weeks in the 39 weeks prior to unemployment. To be eligible for the extension of these wage dependent benefits one needs to have worked at least 4 out of the 5 years prior to unemployment for a minimum of 52 full time days a year. 


\section{The Data}

The data set used contains micro level data for a cohort of Dutch disabled workers. The data (Stelt and Bruinsma, 1997) was collected in light of a government initiated project ${ }^{4}$. Individuals were interviewed on three occasions: one month before possible entry to the disability program, six months after entering the program, and for the last time, two and a half years after entering the program. The first interview took place in October of 1991 and the last interview in May 1994, spanning a period between the two substantial revisions of the disability program. Using the data collected at the three interviews we constructed a panel with thirty-one (monthly) observations. About half our sample is male and on average has one child, 20 years of work experience and 40 years of age. The majority has a relatively low level of education and approximately 3 out of 4 share their lives with a partner. A more accurate picture is sketched in table 5. On a different note, out of the total number of people used in the analysis (983), roughly one third (337) returns to work sometime between November 1991 and May 1994. The remaining observations (646) are censored. There are two occasions where censoring occurs. There are people who participate in the first two interviews but not in the third and last interview. This leads to censoring at the second interview. There are also people who never resume work and are censored at the time of the third interview. Approximately one third of the censored cases (222) happen at the time of the second interview.

${ }^{4}$ PES-III 'Project Evaluation of the revised Social security system' 


\begin{tabular}{|c|c|c|c|c|}
\hline & Mean & St. dev. & Min & Max \\
\hline female dummy & 0.46 & & & \\
\hline \# of children & 0.71 & 1.01 & 0 & 5 \\
\hline last earned wage ${ }^{5}$ & 1951 & 1103 & 165 & 18220 \\
\hline work experience & 22.60 & 11.89 & 1 & 48 \\
\hline elementary school (a) & 0.34 & & & \\
\hline vocational school (b) & 0.29 & & & \\
\hline 4 year high school (c) & 0.09 & & & \\
\hline low education ( 1 if $a, b$ or $c)$ & 0.72 & & & \\
\hline intermediate vocational school (d) & 0.17 & & & \\
\hline 5 year high school $(\mathrm{e})$ & 0.03 & & & \\
\hline medium education ( 1 if $\mathrm{d}$ or $\mathrm{e}$ ) & 0.21 & & & \\
\hline post high school education (f) & 0.06 & & & \\
\hline university education $(\mathrm{g})$ & 0.02 & & & \\
\hline high education ( 1 if $\mathrm{f}$ or $\mathrm{g}$ ) & 0.08 & & & \\
\hline years of schooling & 11.35 & 2.88 & 8 & 19 \\
\hline medium city $(<50,000)$ & 0.17 & & & \\
\hline big city $(>50,000)$ & 0.31 & & & \\
\hline age & 42.13 & 10.83 & 18 & 64 \\
\hline cohabits with partner & 0.77 & & & \\
\hline good health ${ }^{6}$ & 0.10 & & & \\
\hline medium good health & 0.30 & & & \\
\hline medium bad health & 0.29 & & & \\
\hline bad health & 0.31 & & & \\
\hline $\mathrm{N}$ & 983 & & & \\
\hline
\end{tabular}

Table 5. Descriptive statistics (total sample).

\footnotetext{
${ }^{5}$ Last earned wage is the net monthly wage in Dutch guilders. The exchange rate is approximately 1 dollar to two and a half guilders

${ }^{6}$ The respondent was asked to rate his/her overall health status into one of four categories.
} 


\subsection{Nonparticipation in the third and final interview}

There is a substantial number of people that do participate in the first two interviews but choose not to participate in the third and last interview. This might be due to the fact that the last interview takes place two years after the second interview. The problem of censoring is particularly troublesome since it might be the case that especially healthier people, who have returned to work, choose not to participate in the last interview. It could also be the case that the attrition is non-random with respect to other (un)observable characteristics. Table 6 shows the results of a logistic regression of the probability of nonparticipation in the third and last interview on all observable characteristics. The health variables are all based on the question 'do you experience difficulties with .....' resulting in a score of 0,1 or 2 if the person answered no, some, or severe difficulties, respectively. The compounded health variables are constructed by grouping some of the health variables. The variable 'basic motion' is constructed by compounding the variables that indicate difficulties with walking, sitting, standing, and turning. The variable 'heavy motion' is constructed by compounding the variables that indicate difficulties with climbing, kneeling, bending, reaching, and working overhead. Finally, the variable 'communicating' consists of the variable that indicates difficulties with communicating appended by the variables that indicate difficulties with hearing, seeing and talking. The nonparticipation is indeed non-random. Individuals with children, individuals who cohabit and individuals who live in medium or large cities are significantly less likely not to participate in the third and last interview. Individuals who report a conflict at their previous place of employment, or individuals who report their complaints are expected to lessen, are significantly more likely not to participate in the third and last interview. Especially the dropping out of the latter group, individuals who expect their health status to improve, could lead to underestimating the return to work rates since it could be argued that it would be precisely those individuals whose health condition improve, return to work. 


\begin{tabular}{l||c|c|c|}
\cline { 2 - 4 } \multicolumn{1}{l||}{} & \multicolumn{1}{c|}{$\beta$} & $\mathrm{p}$-value & $\mathrm{e}^{\beta}$ \\
\hline & & & \\
female & 0.0525 & 0.8275 & 1.0539 \\
\# of children & -1.1003 & 0.0000 & 0.3328 \\
female*children & -0.3715 & 0.2427 & 0.6897 \\
last earned wage & -0.0001 & 0.3312 & 0.9999 \\
work experience & -0.0068 & 0.6974 & 0.9932 \\
medium education & -0.0070 & 0.9793 & 0.9930 \\
high education & -0.6366 & 0.2372 & 0.5291 \\
years of schooling & -0.0448 & 0.3741 & 0.9562 \\
medium city & -0.4991 & 0.0356 & 0.6071 \\
big city & -0.5904 & 0.0020 & 0.5541 \\
age & 0.0011 & 0.9503 & 1.0011 \\
cohabits with partner & -0.5065 & 0.0151 & 0.6026 \\
medium good health & -0.3218 & 0.3380 & 0.7248 \\
medium bad health & -0.1655 & 0.6271 & 0.8475 \\
bad health & -0.3927 & 0.2656 & 0.6752 \\
conflict & 1.6381 & 0.0000 & 5.1452 \\
difficulties with HH tasks & 0.2178 & 0.1445 & 1.2433 \\
difficulties with basic motion & -0.0256 & 0.6580 & 0.9747 \\
difficulties with heavy motion & -0.0934 & 0.0660 & 0.9109 \\
difficulties with lifting/carrying & 0.1172 & 0.1193 & 1.1243 \\
difficulties with hand/finger & 0.0935 & 0.4780 & 1.0980 \\
difficulties communicating & -0.0294 & 0.7501 & 0.9711 \\
complaints expected to go up & -0.0913 & 0.7159 & 0.9127 \\
complaints expected to go down & 0.5737 & 0.0120 & 1.7748 \\
constant & 0.4225 & 0.7867 & \\
Cox\&Snell $\mathrm{R}^{2}$ & & & \\
Nagelkerke R ${ }^{2}$ & 0.175 & & \\
\hline
\end{tabular}

Table 6. Results of logistic regression on censoring. 


\subsection{A closer look at who returns to work}

Table 7A contains the sample means for those who returned to work before the time of the second interview, those who are censored at the second interview and those who are still in the disability program at the time of the second interview.

\begin{tabular}{r||r|r|r|} 
& $\begin{array}{r}\text { Found job } \\
\text { before } 2^{n d} \\
\text { interview }\end{array}$ & $\begin{array}{l}\text { Censored } \\
\text { at } 2^{\text {nd }} \\
\text { interview }\end{array}$ & $\begin{array}{l}\text { 'Survivors' } \\
\text { at } 2^{\text {nd }} \\
\text { interview }\end{array}$ \\
\hline Female dummy & 0.38 & 0.49 & 0.49 \\
\# of children & 0.70 & 0.19 & 0.91 \\
Last earned wage & 2120 & 1862 & 1926 \\
Work experience & 20.42 & 22.45 & 23.43 \\
Medium education & 0.26 & 0.18 & 0.20 \\
High education & 0.12 & 0.07 & 0.06 \\
Medium city (<50,000) & 0.16 & 0.20 & 0.16 \\
Big city (>50,000) & 0.26 & 0.39 & 0.29 \\
Age & 38.93 & 41.98 & 43.33 \\
Cohabit with partner & 0.71 & 0.79 & 0.79 \\
Good health & 0.19 & 0.08 & 0.08 \\
Medium good health & 0.41 & 0.29 & 0.27 \\
Medium bad health & 0.25 & 0.27 & 0.31 \\
Bad health & 0.15 & 0.36 & 0.34 \\
$\mathrm{~N}$ & & & \\
& 200 & 222 & 561 \\
\hline
\end{tabular}

Table 7A. Sample means.

Table 7B compares those who returned to work after the second interview with those who are still in the disability program at the time of the third interview (i.e. censored at the third interview). Finally, by grouping those who found a job we can compare those who returned to work with those who did not resume work.

\footnotetext{
${ }^{7}$ The first interview was held one month before possible entry to the disability program. The second interview was held six months after entrering the program and the third and last interview was held two and a half years after entering.

${ }^{8}$ Last earned wage is the net monthly nominal wage in Dfl. The exchange rate is approximately 1 dollar to two and a half guilders.

${ }^{9}$ The respondent was asked to rate his/her overall health into one of four catagories.
} 


\begin{tabular}{r|r|r|r|} 
& $\begin{array}{l}\text { Found job } \\
\text { after } 2^{n d} \\
\text { interview }\end{array}$ & $\begin{array}{l}\text { 'Survivors' } \\
\text { at } 3^{\text {rd }} \\
\text { interview }\end{array}$ & $\begin{array}{l}\text { Found } \\
\text { job } \\
\text { (all) }\end{array}$ \\
\hline Female dummy & 0.40 & 0.51 & 0.39 \\
\# of children & 1.09 & 0.85 & 0.86 \\
Last earned wage $^{10}$ & 2049 & 1887 & 2092 \\
Work experience & 18.89 & 24.90 & 19.80 \\
Medium education & 0.28 & 0.17 & 0.26 \\
High education & 0.10 & 0.05 & 0.11 \\
Medium city (<50,000) & 0.14 & 0.17 & 0.15 \\
Big city (>50,000) & 0.26 & 0.30 & 0.26 \\
Age & 37.40 & 45.25 & 38.31 \\
Cohabit with partner & 0.82 & 0.78 & 0.75 \\
Good health & 0.14 & 0.06 & 0.17 \\
Medium good health & 0.40 & 0.23 & 0.40 \\
Medium bad health & 0.26 & 0.32 & 0.26 \\
Bad health & 0.20 & 0.39 & 0.17 \\
$\mathrm{~N}$ & 137 & & \\
& & 424 & 337 \\
\hline
\end{tabular}

Table 7B. Sample means.

Those who do return to work are predominantly (younger) men with relatively high last earned wages and are more likely to be higher educated. Perhaps not surprising, those who returned to work also reported to have better overall health. Those people who are still in the disability program and have not returned to work by the time of the third interview are generally older, have relatively low last earned wages, are generally less educated and report relatively poor overall health. In tables $8 \mathrm{~A}$ and $8 \mathrm{~B}$ we make a further distinction by disability. Besides the patterns observed in tables $7 \mathrm{~A}$ and $7 \mathrm{~B}$ we see that women appear to be less often disabled. One other interesting finding is that the majority of people that do return to work are still disabled. Once again, it's important to remind ourselves that disability applies to a loss in earning capacity. If you are only able to return to work part-time, the loss in income will still cause you to be considered disabled. Another cautionary point related to the definition of disability is that it is much easier to become or stay disabled for someone who had a relatively high level of last earned wages. We also observe that feature in tables $8 \mathrm{~A}$ and $8 \mathrm{~B}$. Without exception, those who are disabled have higher average levels of last earned wages than do non-disabled. Recall that the level of disability is computed by comparing your previous earning level with your remaining earning potential. This remaining earning potential is computed based on earnings in jobs that one would still be able to perform.

\footnotetext{
${ }^{10}$ Last earned wage is the net monthly nominal wage in Dfl. The exchange rate is approximately 1 dollar to two and a half guilders.

${ }^{11}$ The respondent was asked to rate his/her overall health into one of four catagories.
} 
It is therefore plausible that it is easier to become or stay disabled for a person with a relatively high level of previous earnings. This can be made clear by the following example. Consider two identical individuals. One is a high wage earner whereas the other is a low wage earner. When their disability status is to be determined, both individuals will have the same absolute remaining earning capacity, but the high wage earner will be considered more disabled in the Dutch disability program since the relative loss of earning capacity is greater. It seems then, that people with high paying jobs would disproportionately benefit from the disability program. However, in the good social tradition they also pay a higher premium.

\begin{tabular}{r|r|r|r|} 
& $\begin{array}{l}\text { Censored at } \\
2^{\text {nd }} \text { interview } \\
\text { (disabled) }\end{array}$ & $\begin{array}{l}\text { Censored at } \\
2^{\text {nd interview }} \\
\text { (not disabled) }\end{array}$ & $\begin{array}{l}\text { 'survivor' at } \\
3^{r d} \text { interview } \\
\text { (disabled) }\end{array}$ \\
\hline & & & \\
Female dummy & 0.47 & 0.59 & 0.44 \\
\# of children & 0.16 & 0.30 & 0.86 \\
Last earned wage & 1910 & 1678 & 2034 \\
Work experience & 23.85 & 17.10 & 27.31 \\
Medium education & 0.19 & 0.13 & 0.18 \\
High education & 0.07 & 0.09 & 0.05 \\
Medium city (10 - 50,000) & 0.18 & 0.26 & 0.17 \\
Big city (>50,000) & 0.41 & 0.33 & 0.31 \\
Age & 43.51 & 36.11 & 46.87 \\
Cohabit with partner & 0.78 & 0.80 & 0.79 \\
Good health & & 0.11 & 0.05 \\
Medium good health & 0.07 & 0.39 & 0.22 \\
Medium bad health & 0.26 & 0.28 & 0.30 \\
Bad health & 0.27 & 0.22 & 0.42 \\
& 0.39 & & \\
$\mathrm{~N}^{14}$ & 176 & 46 & 329 \\
\hline
\end{tabular}

Table 8A. Sample means for sub groups.

\footnotetext{
${ }^{12}$ Last earned wage is the net monthly wage in Dutch guilders. The exchange rate is approximately 1 dollar to two and a half guilders

${ }^{13}$ The respondent was asked to rate his/her overall health status into these four catagories

${ }^{14}$ Out of the 983 observations we had 6 missing values for disability status.
} 


\begin{tabular}{r|r|r|l|} 
& $\begin{array}{l}\text { 'survivor' at } \\
3^{\text {rdinterview }} \\
\text { (not disabled) }\end{array}$ & $\begin{array}{l}\text { Did } \\
\text { resume } \\
\text { (disabled) }\end{array}$ & $\begin{array}{l}\text { Did } \\
\text { resume } \\
\text { (not disabled) }\end{array}$ \\
\hline & & & \\
Female dummy & 0.78 & 0.27 & 0.56 \\
\# of children & 0.80 & 0.95 & 0.74 \\
Last earned wage ${ }^{15}$ & 1375 & 2294 & 1780 \\
Work experience & 16.55 & 22.99 & 14.96 \\
Medium education & 0.15 & 0.24 & 0.30 \\
High education & 0.05 & 0.11 & 0.11 \\
Medium city (10 - 50,000) & 0.16 & 0.14 & 0.17 \\
Big city (>50,000) & 0.29 & 0.23 & 0.30 \\
Age & 39.64 & 40.92 & 34.33 \\
Cohabit with partner & 0.74 & 0.81 & 0.69 \\
Good health & 0.13 & 0.13 & 0.22 \\
Medium good health & 0.23 & 0.40 & 0.41 \\
Medium bad health & 0.37 & 0.27 & 0.23 \\
Bad health & 0.27 & 0.19 & 0.14 \\
$\mathrm{~N}^{17}$ & & & \\
& 95 & 198 & 133 \\
\hline
\end{tabular}

Table 8B. Sample means for sub groups.

\footnotetext{
${ }^{15}$ Last earned wage is the net monthly wage in Dutch guilders. The exchange rate is approximately 1 dollar to two and a half guilders

${ }^{16}$ The respondent was asked to rate his/her overall health status into these four catagories

${ }^{17}$ Out of the 983 observations we had 6 missing values for disability status.
} 


\subsection{Hazard rates of exits into employment}

Table 9 is a life table detailing the number of people in each period who returned to work during that period. Not surprisingly, the probability of returning to work declines over time. There are two effects that contribute to this observed pattern of a declining probability of returning to work. The one effect is often described as a stigma effect, meaning that it is increasingly harder to find a job, the longer one has been inactive, since employers take this as a bad signal. On the other hand, those people with the best chances of returning to work are also the first ones to do so, leaving behind a group of people with increasingly unfavorable characteristics. It might also be the case that people over time become more and more complacent and stop looking for (re-) employment. Figure 2 is a graphical representation of the hazard rate in table 9 . The probability of returning to work gradually drops from $6 \%$ to about $1 \%$ during the first year and a half, after which it levels out.

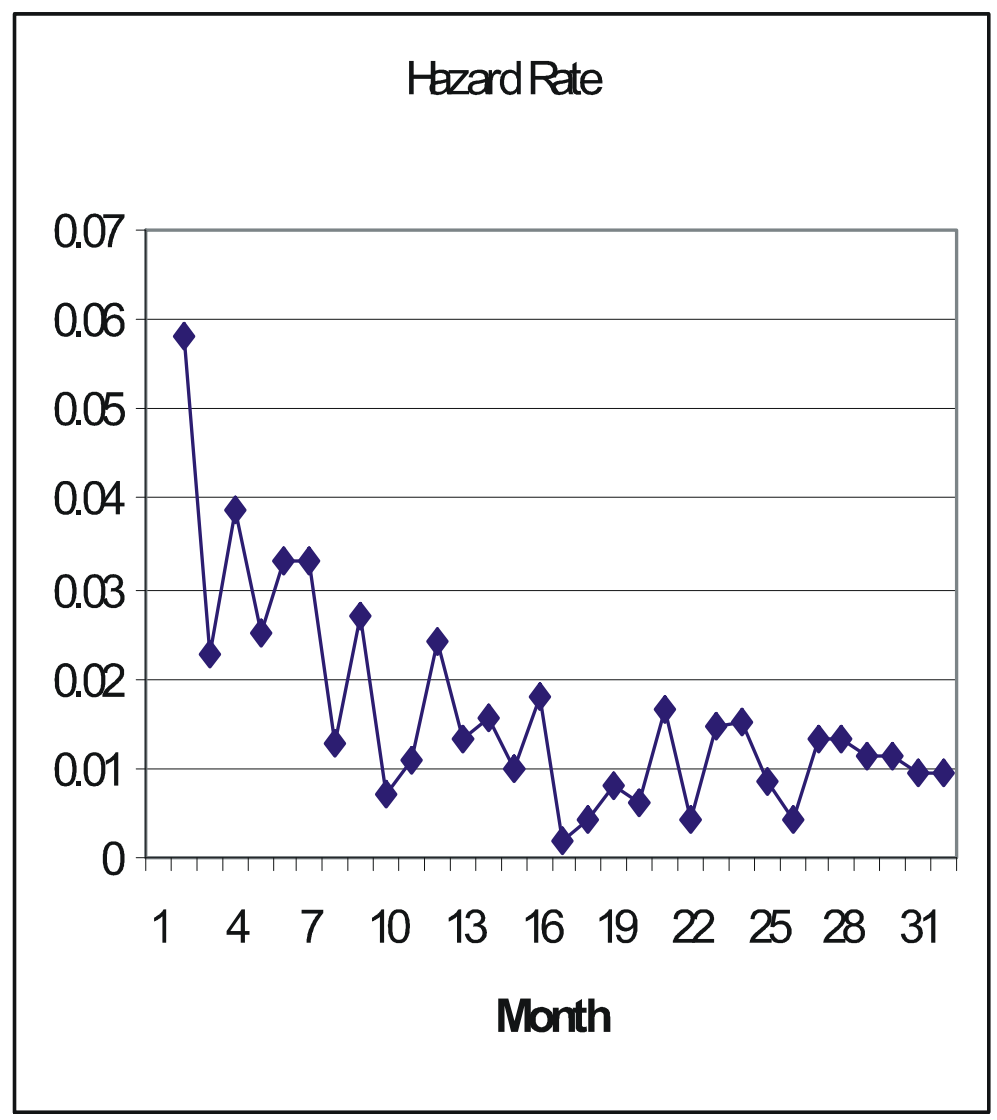

Figure 2. Life table hazard rates over time. 


\begin{tabular}{r|c|c|c|c|c|c|} 
Month & $\begin{array}{l}\text { entering } \\
\text { interval }\end{array}$ & $\begin{array}{l}\text { drop } \\
\text { out }\end{array}$ & $\begin{array}{l}\text { exposed } \\
\text { to risk }\end{array}$ & $\begin{array}{l}\text { found } \\
\text { job }\end{array}$ & $\begin{array}{l}\text { hazard } \\
\text { rate }\end{array}$ & $\begin{array}{l}\text { s.e. of } \\
\text { hazard rate }\end{array}$ \\
\hline 1 & 983 & 0 & 983 & 57 & 0.0580 & 0.0079 \\
2 & 926 & 0 & 926 & 21 & 0.0227 & 0.0050 \\
3 & 905 & 0 & 905 & 35 & 0.0387 & 0.0067 \\
4 & 870 & 0 & 870 & 22 & 0.0253 & 0.0055 \\
5 & 848 & 0 & 848 & 28 & 0.0330 & 0.0063 \\
6 & 820 & 0 & 820 & 27 & 0.0329 & 0.0064 \\
7 & 793 & 222 & 793 & 10 & 0.0126 & 0.0057 \\
8 & 561 & 0 & 561 & 15 & 0.0267 & 0.0070 \\
9 & 546 & 0 & 546 & 4 & 0.0073 & 0.0037 \\
10 & 542 & 0 & 542 & 6 & 0.0111 & 0.0045 \\
11 & 536 & 0 & 536 & 13 & 0.0243 & 0.0068 \\
12 & 523 & 0 & 523 & 7 & 0.0134 & 0.0051 \\
13 & 516 & 0 & 516 & 8 & 0.0155 & 0.0055 \\
14 & 508 & 0 & 508 & 5 & 0.0098 & 0.0044 \\
15 & 503 & 0 & 503 & 9 & 0.0179 & 0.0060 \\
16 & 494 & 0 & 494 & 1 & 0.0020 & 0.0020 \\
17 & 493 & 0 & 493 & 2 & 0.0041 & 0.0029 \\
18 & 491 & 0 & 491 & 4 & 0.0081 & 0.0041 \\
19 & 487 & 0 & 487 & 3 & 0.0062 & 0.0036 \\
20 & 484 & 0 & 484 & 8 & 0.0165 & 0.0059 \\
21 & 476 & 0 & 476 & 2 & 0.0042 & 0.0030 \\
22 & 474 & 0 & 474 & 7 & 0.0148 & 0.0056 \\
23 & 467 & 0 & 467 & 7 & 0.0150 & 0.0057 \\
24 & 460 & 0 & 460 & 4 & 0.0087 & 0.0044 \\
25 & 456 & 0 & 456 & 2 & 0.0044 & 0.0031 \\
26 & 454 & 0 & 454 & 6 & 0.0132 & 0.0054 \\
27 & 448 & 0 & 448 & 6 & 0.0134 & 0.0055 \\
28 & 442 & 0 & 442 & 5 & 0.0113 & 0.0051 \\
29 & 437 & 0 & 437 & 5 & 0.0114 & 0.0051 \\
30 & 432 & 0 & 432 & 4 & 0.0093 & 0.0047 \\
31 & 428 & 0 & 428 & 4 & 0.0093 & 0.0048 \\
\hline
\end{tabular}

Table 9. Life table. 


\section{A behavioral labor supply model}

The underlying economic model of the decision to return to work can be described as a basic job search model where people receive job offers that they can accept or decline. We specify a behavioral model with forward looking individuals as a proxy for the underlying economic model. In this model, the individual receives offers which he can accept or reject. We make the simplifying assumption that once you accept a job you will keep this job in consecutive periods. If we would not make this assumption, the decision to accept a job at any given time will enter in the Bellman equation, greatly complicating the model. To check the validity of the assumption that once you accept a job you keep this job forever, we looked at what the individuals reported on their earnings after they resumed work. We found that out of the 315 people that resumed work, 21 people reported lower earnings at some point after they resumed. Out of these 21 people, 13 people did so because of a termination of employment. Out of the 315 people that resumed work, 31 people reported higher earnings at some point after they resumed work.

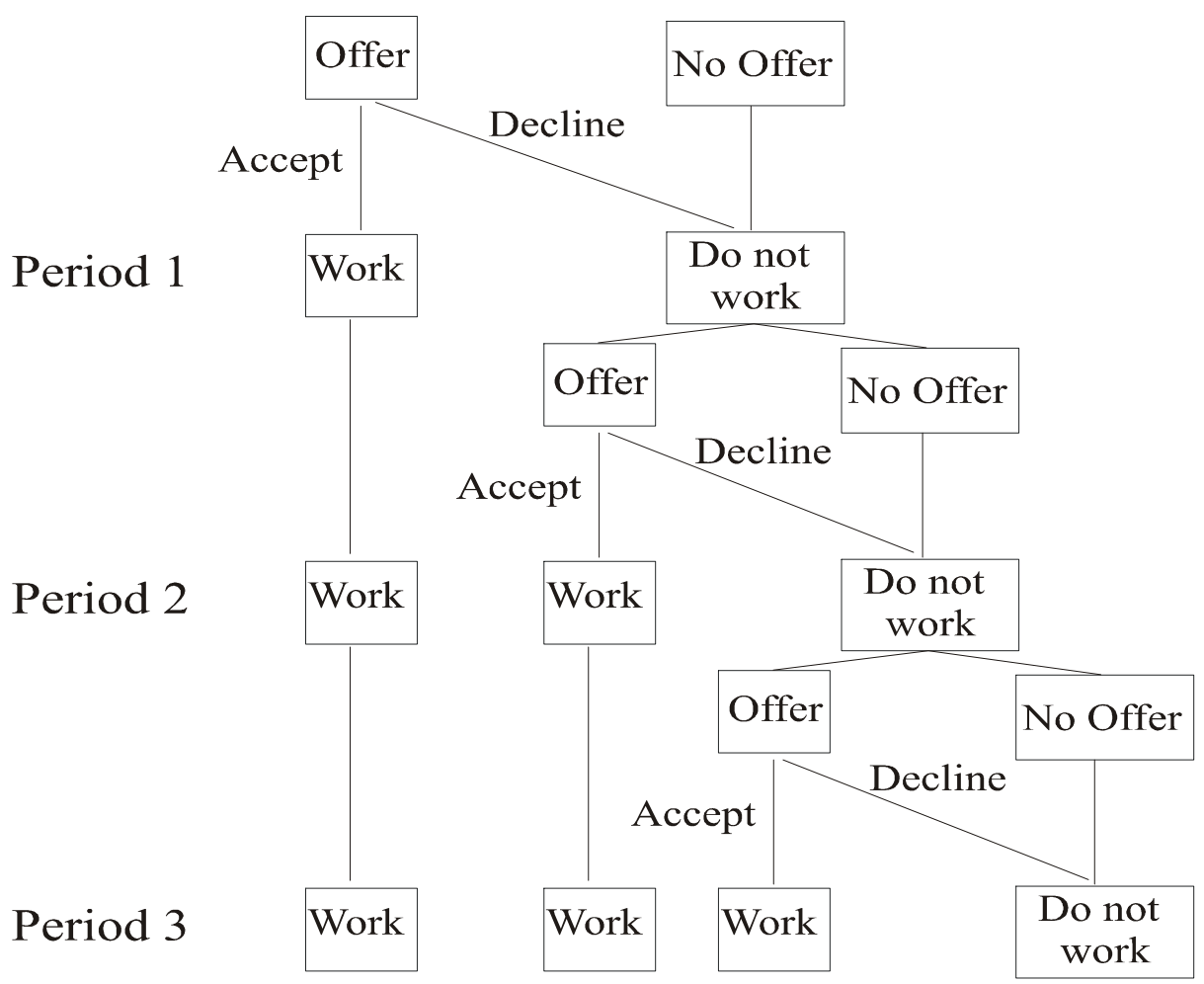


The goal of the individual is to maximize expected discounted lifetime utility denoted as:

$$
E \sum_{t=1}^{T} \delta^{t-1} U\left(P_{t}, C_{t}\right)
$$

where $\mathrm{P}_{t}$ is 1 if you decide to work in period $\mathrm{t}$ and 0 otherwise. $\mathrm{C}_{t}$ is the level of consumption in period $t$. We do not allow for savings in our model so consumption equals earnings in each period. The utility function is assumed to take the following simple linear form:

$$
U\left(P_{t}, C_{t}\right)=C_{t}-b * I\left(P_{t}=1\right)
$$

where $\mathrm{b}$ is the disutility of working (that can be negative).

Let

$$
b=\beta_{0}+X^{\prime} \beta_{1}
$$

where X contains the individual's characteristics. This will allow for people with different characteristics to have a different disutility of working.

Furthermore, let

$$
\begin{aligned}
& C_{t}=W_{t} * I\left(P_{t}=1\right)+D B_{t}\left(L E W, D C_{t}, W_{t}, P_{t}\right)+ \\
& U B_{t}\left(L E W, \text { Age, Experience, } t, D B_{t}\right) * I\left(P_{t}=0\right)
\end{aligned}
$$

where $\mathrm{W}_{t}$ are the wage earnings in period t if working. $\mathrm{DB}_{t}$ are the disability benefits at time $t$ which are a function of the last earned wage (LEW), the wage earnings in period $t\left(\mathrm{~W}_{t}\right)$ and the disability class at period $\mathrm{t}\left(\mathrm{DC}_{t}\right)$. It is possible to work and still receive disability benefits. When a worker in the disability program accepts employment he is automatically re-evaluated. The unemployment benefits will stop, but the newly determined disability level could still entitle him to disability benefits. This will be the case when the new earning capacity, based on the new (accepted) wage, would still imply a disability level of $15 \%$ or more. The disability benefits thus depend on the employment decision, $\mathrm{P}_{t}$, as well. $\mathrm{UB}_{t}$ are the unemployment benefits at time $\mathrm{t}$ which are a function of the last earned wage, age, the amount of work experience as well as the disability benefits and the duration in the program at time t. The wage offer equation is given by

$$
W_{t}=Z_{t}^{\prime} \gamma_{1}+D_{t}^{\prime} \gamma_{2}+\nu_{t}
$$

where $\mathrm{Z}_{t}$ includes ability variables (education, sex, age etc.) and $\mathrm{D}_{t}$ contains variables related to the individual's work history (number of years of work experience etc.). The error term $\nu_{t}$ is distributed normal with mean zero and variance $\sigma_{\nu}^{2}$. Finally, the job offer probability is specified as:

$$
\Phi\left(Y_{t}^{\prime} \lambda\right)
$$

where $\mathrm{Y}_{t}$ includes individual characteristics such as sex, age, education and work experience, as well as a time trend. 


\subsection{The Benefits}

\subsubsection{The Disability benefits}

The disability benefits are always a fraction of the last earned wage (or a maximum) depending on the level of disability. Each disability class corresponds directly to an appropriate share. Table 10 displays these shares for the different disability classes

\begin{tabular}{c|l|l|} 
& & $\begin{array}{l}l_{j}: \\
\text { corresponding fraction of last } \\
\text { earned wage (or maximum) } \\
\text { comprising Disability Benefits (DB) }\end{array}$ \\
\hline 1 & \% disabled & 0 \\
2 & {$[0,15)$} & 0.14 \\
3 & {$[15,25)$} & 0.21 \\
4 & {$[25,35)$} & 0.28 \\
5 & {$[35,45)$} & 0.35 \\
6 & {$[45,55)$} & 0.42 \\
7 & {$[55,65)$} & 0.5075 \\
8 & {$[65,80)$} & 0.70 \\
\hline
\end{tabular}

Table 10. Replacement rates for different disability classes.

We can then express the disability benefits (DB) as

$$
D B_{t}=\sum_{j=1}^{8} l_{j} * \min (\text { lew, max wage }) * I\left(D C_{t}=j\right)
$$

where $l_{j}$ is the fraction of the last earned wage (lew) one gets depending on which of the eight different disability brackets one is in. $\mathrm{I}\left(\mathrm{DC}_{t}=j\right)$ is an indicator function which is 1 if the individual is in disability class $\mathrm{j}$ in period $\mathrm{t}$.

\subsubsection{The Unemployment Benefits}

The unemployment benefits consist of three stages. The first stage is the stage in which the unemployment benefits consist of a fraction of the last earned wage (or a maximum). The second stage is a continuation of the unemployment benefits based on the minimum wage and the third stage is a continuation of the unemployment benefits based on the minimum wage subject to a means test. We can write the unemployment benefits at time $\mathrm{t}\left(\mathrm{UB}_{t}\right)$ as

$$
U B_{t}=U B_{1 t} * D_{1 t}+U B_{2 t} * D_{2 t}+U B_{3 t} * D_{3 t}
$$


where $D_{1}, D_{2}$ and $D_{3}$ are dummy variables indicating if an individual is in the first, second or third stage respectively. The $\mathrm{UB}_{1}, \mathrm{UB}_{2}$, and $\mathrm{UB}_{3}$ correspond to the different unemployment benefits in the three different stages. Hence,

$$
\begin{aligned}
& U B_{1 t}=\sum_{j=1}^{8} I\left(D C_{t}=j\right) *\left(0.7-l_{j}\right) * \min (\text { lew, max wage }) \\
& U B_{2 t}=\sum_{j=1}^{8} I\left(D C_{t}=j\right) *\left(0.7-l_{j}\right) * \min (\text { lew }, \text { min wage })
\end{aligned}
$$

and

$$
\begin{array}{r}
U B_{3 t}=\sum_{j=1}^{8} I\left(D C_{t}=j\right) * \min \left(\begin{array}{r} 
\\
{\left[\max \left\langle 0,\left(0.7 * \min \text { wage }-l_{j} * \min (\text { lew, max wage })\right)\right\rangle\right],} \\
\left.\left[\left(\left(0.7-l_{j}\right) * \min (\text { lew, min wage })\right)\right]\right)
\end{array}\right.
\end{array}
$$

where minwage is the applicable minimum wage one is entitled to depending on age ${ }^{18}$. The dummy variables indicating which stage of the unemployment benefit applies, are straightforward. Let the variable 'high-time' denote the duration in months of the first stage. This duration depends on the level of work experience (in years). Table 11 below lists these possible durations.

\begin{tabular}{c|c|} 
& $\begin{array}{c}\text { hightime: duration of first stage } \\
\text { work experience (years) }\end{array}$ \\
\hline less then 5 & 6 \\
5 or more & 9 \\
10 or more & 12 \\
15 or more & 18 \\
20 or more & 24 \\
25 or more & 30 \\
30 or more & 36 \\
35 or more & 48 \\
40 or more & 60 \\
\hline
\end{tabular}

Table 11. Extension of first stage (high) unemployment benefits.

\footnotetext{
${ }^{18}$ Recall that minimum wage is age dependent. For people under 23 the minimum wage is only a fraction of the minimum wage for adults 23 and over. For different age groups these fractions are:

\begin{tabular}{l|l|l|l|l}
$18-19$ & $19-20$ & $20-21$ & $21-22$ & $22-23$ \\
\hline $45.5 \%$ & $52.5 \%$ & $61.5 \%$ & $72.5 \%$ & $85 \%$
\end{tabular}
}


Hence

$$
\begin{gathered}
D_{1 t}=I(t \leq \text { hightime }) \\
\begin{aligned}
D_{2 t}=I(\text { hightime }<t \leq \text { hightime }+12 * & I(\text { startage }<57.5) \\
& +40 * I(\text { startage } \geq 57.5))
\end{aligned}
\end{gathered}
$$

and

$$
D_{3 t}=I\left(D_{1 t}=0\right) * I\left(D_{2 t}=0\right)
$$

where $\mathrm{t}$ is denoted in months and startage is the individual's age in years at the onset of unemployment. 


\subsection{The decision to return to work : Solving the model}

At the very start of the disability program, a labor market professional, together with a medical professional, assesses your 'potential remaining earning capacity'. When you accept a job, you are automatically re-evaluated and you will lose any unemployment benefits that you might have been receiving. If you happen to have found a job with a wage that exceeds the earlier 'potential remaining earning capacity', then your level of disability will be re-calculated using this new (higher) wage as your new (higher) remaining earning capacity. Conversely, if you accepted a job with a wage that is lower than the previous 'remaining potential earning capacity', no adjustments will be made. This implies that you can never go up a disability bracket, only down ${ }^{19}$. When accepting a job offer a person thus has to incorporate what this will mean for his disability level. It might be the case that the new job will reduce the level of disability below 15 $\%$. In that case, accepting the offer would mean losing all disability benefits in addition to any unemployment benefits. It can also be the case that the level of disability will be reduced, but not enough to eliminate all disability benefits. In that case, a person is still entitled to disability benefits even when accepting the offer. In short, each time an individual receives a job offer, he can compute his total earnings if he were to accept that wage. This is best captured graphically. Figure 3 is the case for a fully disabled person. The horizontal axes represents the wage offer and the vertical axes represents total income. Total income is income from employment plus any remaining disability benefits if there are any. The units are measured in Dfl. but are expressed as a fraction of the last earned wage. This is done as to easily represent the benefit structure. These disability benefits are represented as the dotted vertical bars. The 45 degree line is the income from employment. Consider a fully disabled person. When this person accepts a wage offer of $20 \%$ or less than his last earned wage, he will still get to keep all of his benefits since he would still be considered $80 \%$ or more disabled when re-evaluated. When the wage offer increases, the re-evaluation will result in a lower disability class, up to the point that the wage offer no longer gives rise to any disability benefits if he were to accept. This is the case when the wage offer is at least $85 \%$ of his last earned wage. As a result of the benefits structure, the total income when accepting different wage offers, is represented by the jagged shaped line. Figure 4 is the same graph, but now for a partially $(50 \%)$ disabled person. The described process of total income dropping at particular values for the wage offer (if accepted) is now limited in the sense that there are fewer of these drops. In the case of a person who is deemed not disabled, the jagged total income line will collapse to the 45 degree line.

\footnotetext{
${ }^{19}$ In reality, there is a chance to go up in disability class when re-evaluated. It is also possible to be re-evaluated without starting a job. However, these are more rare exceptions than the rule.
} 


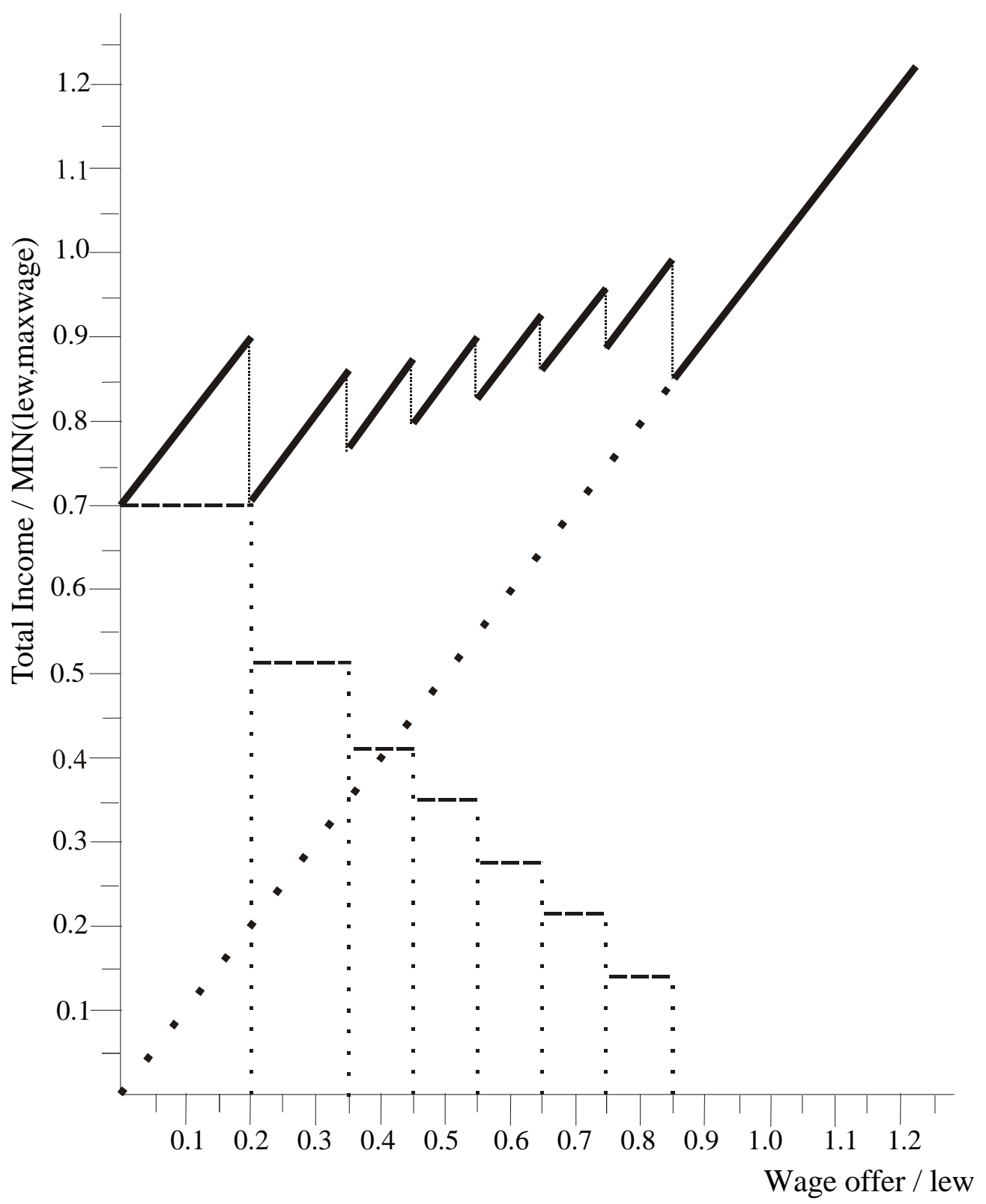

Figure 3. Total income (wage and benefits) when accepting different wage offers (fully disabled, disability class $=8$ ) 


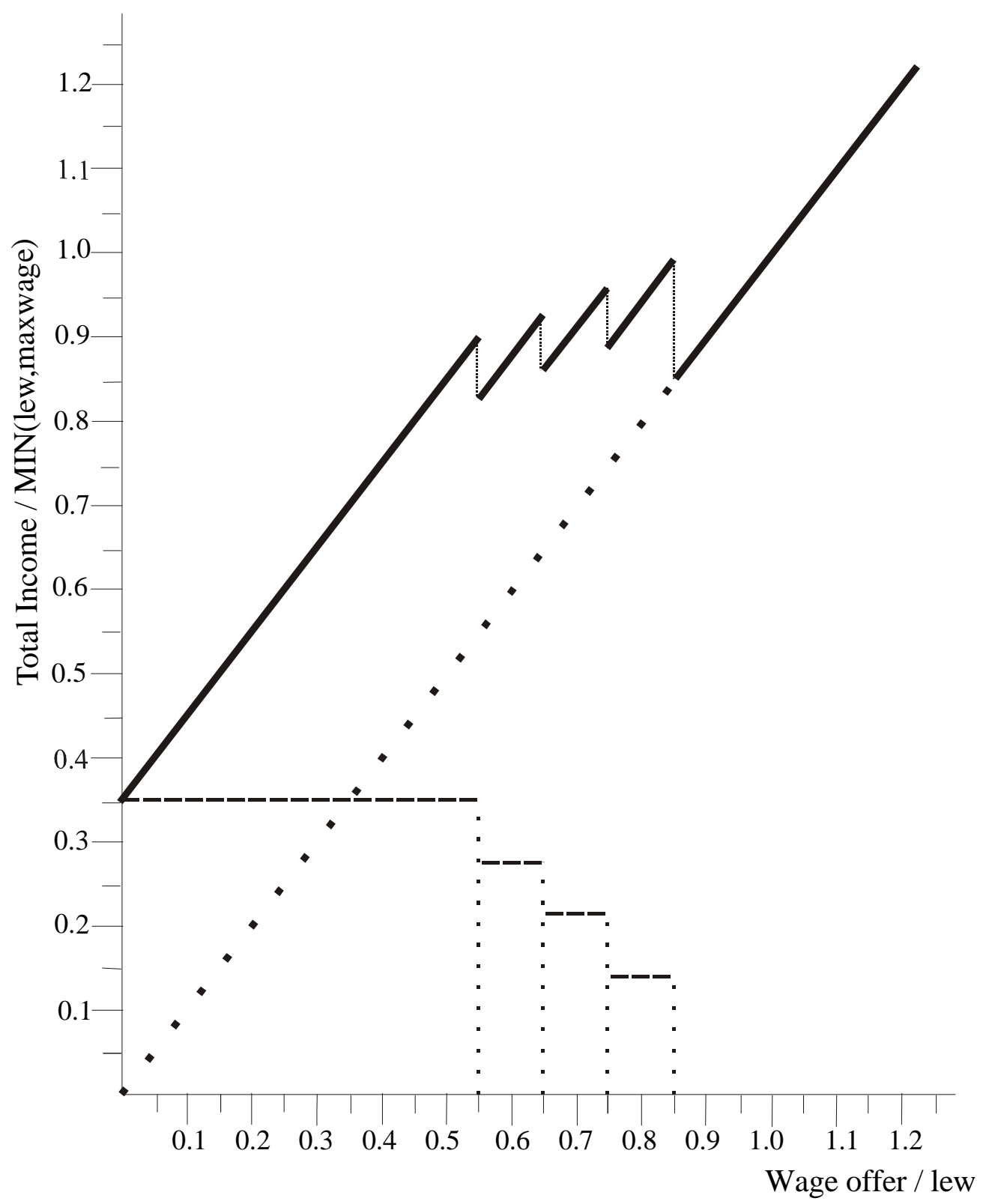

Figure 4. Total income (wage and benefits) when accepting different wage offers (partially disabled, disability class $=5$ ) 
To answer the question which wages one should accept in which period, we need to solve the model. Total discounted lifetime utility is maximized conditionally on the current disability class that is treated as given. The model can then be easily solved by using backward recursion. Consider an individual at the start of the last period $(\mathrm{T})$ who received a job offer with wage $\mathrm{W}_{T}$. He will then accept the job if

$$
W_{T}+D B_{T}\left(W_{T}\right)-b \geq D B_{T}+U B_{T}
$$

or

$$
W_{T}+D B_{T}\left(W_{T}\right) \geq D B_{T}+U B_{T}+b
$$

We write $D B_{T}\left(W_{T}\right)$ to indicate that the remaining disability benefits when accepting a job depend on the accepted wage ${ }^{20}$. The left-hand side of the inequality corresponds to the fat line in figures 3 and 4 . The right-hand side is known to the individual and could be visualized in the same graph by a horizontal line. You accept those wages for which the fat line lies above this imaginary horizontal line. In the classic job search model, we accept wages if they exceed a certain reservation wage. Because of the disability brackets, and the resulting jagged shaped left-hand-side, that is not necessarily the case here, since the left hand side of the above equation can be decreasing in $\mathrm{W}_{t}$ over certain ranges. However, we can express the set of acceptable wages $\left(\mathrm{S}_{T}\right)$ as a set of eight or less disjoint intervals ${ }^{21}$. The expected remaining lifetime utility at period $\mathrm{T}$ can then be computed as:

$$
A_{T}=U\left(0, C_{T}\right) *\left[P_{r}\left(W_{T} \notin S_{T}\right) * \lambda_{T}+\left(1-\lambda_{T}\right)\right]+\lambda_{T} * E_{S_{T}} U\left(1, C_{T}\right)
$$

where $\lambda_{T}$ is the probability of receiving a job offer in period $\mathrm{T}$ and $E_{S_{T}}$ denotes the expectation over the set of acceptable wages denoted by $S_{T}$. The work decision equation in period $\mathrm{T}-1$ is similar. You accept a job with wage $\mathrm{W}_{T-1}$ in period $\mathrm{T}-1$ if

$$
(1+\delta) *\left[W_{T-1}+D B_{T-1}\left(W_{T-1}\right)-b\right] \geq D B_{T-1}+U B_{T-1}+\delta * A_{T}
$$

or

$$
W_{T-1}+D B_{T-1}\left(W_{T-1}\right) \geq \frac{1}{(1+\delta)} *\left[D B_{T-1}+U B_{T-1}+\delta * A_{T}\right]+b
$$

\footnotetext{
${ }^{20}$ The unemployment benefits and the disability benefits when not working are represented simply by UB and DB, respectively, for notational convenience.

${ }^{21}$ See appendix
} 
With the new right-hand side we can now compute our set of acceptable wages for period $\mathrm{T}-1$ denoted as $\mathrm{S}_{T-1}$. This in turn allows us to compute the expected remaining lifetime utility at period $\mathrm{T}-1$ as:

$$
\begin{array}{r}
A_{T-1}=\left[U\left(0, C_{T-1}\right)+\delta * A_{T}\right] *\left[P_{r}\left(W_{T-1} \notin S_{T-1}\right) * \lambda_{T-1}+\left(1-\lambda_{T-1}\right)\right]+ \\
\lambda_{T-1} *(1+\delta) * E_{S_{T-1}} U\left(1, C_{T-1}\right)
\end{array}
$$

More generally, in any period $\mathrm{t}$ we accept jobs with wages $W_{t}$ if

$$
W_{t}+D B_{t}\left(W_{t}\right) \geq \frac{1}{\left(1+\delta+. .+\delta^{t}\right)} *\left[D B_{t}+U B_{t}+\delta * A_{t+1}\right]+b
$$

Also,

$$
\begin{aligned}
A_{t}=\left[U\left(0, C_{t}\right)+\delta * A_{t+1}\right] * & {\left[P_{r}\left(W_{t} \notin S_{t}\right) * \lambda_{t}+\left(1-\lambda_{t}\right)\right]+} \\
& \lambda_{t} *\left(1+\delta+. .+\delta^{t}\right) * E_{S_{t}} U\left(1, C_{t}\right)
\end{aligned}
$$




\subsection{Data limitations}

We addressed the attrition in the sample due to nonparticipation in the third and last interview. For the purpose of the empirical analysis we need not only information at the time of the interview, but also enough information to construct the level of benefits and the percent disabled for the periods in between the interviews. We lose 99 out of the 983 observations due to incomplete data. Because this too, like the non participation in the third and last interview, could potentially be non random we did another logistic regression on the incurrence of incomplete data. The results are reported in table 12 . The results indicate that the observations deleted due to incomplete data, do not seem to be characterized by a particular set of observable characteristics.

\begin{tabular}{l|r|r|r|}
\cline { 2 - 4 } \multicolumn{1}{l||}{} & \multicolumn{1}{c|}{$\beta$} & $\mathrm{p}$-value & $\mathrm{e}^{\beta}$ \\
\hline female & 0.3205 & 0.3525 & 1.3778 \\
\# of children & -0.1086 & 0.4894 & 0.8971 \\
female*children & 0.0837 & 0.7114 & 1.0873 \\
last earned wage & -0.0001 & 0.3809 & 0.9999 \\
work experience & -0.0362 & 0.0859 & 0.9645 \\
medium education & 0.2615 & 0.4879 & 1.2988 \\
high education & -1.0062 & 0.1294 & 0.3656 \\
years of schooling & -0.0907 & 0.1572 & 0.9133 \\
medium city & 0.1822 & 0.5570 & 1.1999 \\
big city & 0.2877 & 0.2698 & 1.3334 \\
age & 0.0351 & 0.0938 & 1.0357 \\
cohabits with partner & -0.4268 & 0.1509 & 0.6526 \\
medium good health & -0.4193 & 0.3090 & 0.6575 \\
medium bad health & -0.1389 & 0.7476 & 0.8703 \\
bad health & -0.4424 & 0.3317 & 0.6490 \\
conflict & -0.2605 & 0.3784 & 0.7706 \\
difficulties with HH tasks & 0.0623 & 0.7534 & 1.0643 \\
difficulties with basic motion & -0.0463 & 0.5441 & 0.9548 \\
difficulties with heavy motion & -0.0236 & 0.7169 & 0.9767 \\
difficulties with lifting/carrying & 0.0203 & 0.8341 & 1.0205 \\
difficulties with hand/finger & -0.2225 & 0.2511 & 0.8005 \\
difficulties communicating & -0.2332 & 0.1042 & 0.7920 \\
complaints expected to go up & 0.3752 & 0.3253 & 1.4553 \\
complaints expected to go down & 0.2155 & 0.4247 & 1.2404 \\
constant & -0.5918 & 0.7590 & \\
Cox\&Snell R ${ }^{2}$ & & & \\
Nagelkerke R ${ }^{2}$ & 0.023 & & \\
\hline Table $12 . ~ R e$ & \\
& 0.048 & & \\
\hline
\end{tabular}

Table 12. Results of a logistic regression on incidence of missing data. 


\section{Results of Estimation}

The model specifications include different sets of health variables as well as personal characteristics such as age and education. The health variables are all based on the question 'do you experience difficulties with .....' resulting in a score of 0,1 or 2 if the person answered no, some, or severe difficulties, respectively. The compounded health variables are constructed by grouping some of the health variables. The variable 'basic motion' is constructed by compounding the variables that indicate difficulties with walking, sitting, standing, and turning. The variable 'heavy motion' is constructed by compounding the variables that indicate difficulties with climbing, kneeling, bending, reaching, and working overhead. Finally, the variable 'communicating' consists of the variable that indicates difficulties with communicating appended by the variables that indicate difficulties with hearing, seeing and talking. Two variables that warrant special attention are the variable percent disabled and the variable benefits. Both variables are time variant. Benefits are the total benefits a person is receiving when not working. These consist of the sum of the disability benefits and the unemployment benefits. The percent disabled is taken as the midpoint of the appropriate disability class the individual is in. Since the percent disabled measures the loss in earning capacity it is by construction a variable capturing physical limitations or heath status on the one hand, and economic conditions on the other. This can be made clear by the following example. Consider two identical individuals. One is a high wage earner whereas the other is a low wage earner. When their disability status is to be determined, both individuals will have the same absolute remaining earning capacity, but the high wage earner will be considered more disabled in the Dutch disability program since the relative loss of earning capacity is greater.

\subsection{Health variables in the wage offer}

Tables 13 through 17 contain the estimation results for different model specifications. Health status influences productivity and hence affects wages, but what affects productivity should also be expected to affect the probability of receiving an offer. Table 13 contains the specifications where we include health variables only in our wage offer equation. What we find is that there is a strong and significant pay off to education. Another robust finding is that women earn about one standard deviation less than their male counterparts. We do not find any significant effect of health variables on the wage offer, although they do have the expected signs. When including all health variables and choosing a logaritmic rather than a quadratic specification for work experience and age, we do find a negative effect for the variable indicating difficulties using hands and fingers. We also find that, conditional on all other variables, people who report the worst health status are also the ones with the lowest wage offer. Regarding the offer probability, we find a significant negative effect of the time spent in the program. This is not surprising. If one is out of the active labor force for a substantial amount of time, then it is difficult to return to work due to stigma 
effects. Even in today's labor market in the Netherlands, very few people who have been unemployed or disabled and not working for a prolonged period of time find new employment. We also find a significant disutility of working of about Dfl. 300 per month.

\begin{tabular}{|c|c|c|c|}
\hline wage offer & $\mathrm{I}$ & II & III \\
\hline constant & $3079.543(3.05)$ & $3072.105(3.10)$ & $828.525(0.82)$ \\
\hline work experience / 5 & $591.331(3.95)$ & $508.966(3.48)$ & \\
\hline (work experience / 5$)^{2}$ & $-58.070(3.28)$ & $-49.495(2.81)$ & \\
\hline $\log ($ work experience) & & & $302.687(2.30)$ \\
\hline age/10 & $-865.681(2.62)$ & $-972.525(2.96)$ & \\
\hline$(\text { age } / 10)^{2}$ & $56.539(2.58)$ & $64.377(2.94)$ & \\
\hline $\log ($ age $)$ & & & $-132.115(0.36)$ \\
\hline years of education & $98.654(6.22)$ & $131.932(9.19)$ & $94.428(6.55)$ \\
\hline female & $-714.439(6.99)$ & $-660.357(6.65)$ & $-671.593(7.11)$ \\
\hline difficulties with: & & & \\
\hline basic motion & $-28.245(0.95)$ & & $-19.234(0.68)$ \\
\hline · hand/finger & $-49.317(0.49)$ & & $-185.887(2.17)$ \\
\hline $\begin{array}{l}\text { other then hand/finger } \\
\text { or basic motion }\end{array}$ & $-12.880(1.01)$ & & $-9.840(0.78)$ \\
\hline medium good health & & $-99.071(0.86)$ & $76.682(0.67)$ \\
\hline medium bad health & & $-131.597(1.02)$ & $-15.531(0.12)$ \\
\hline bad health & & $-53.631(0.40)$ & $-266.037(1.87)$ \\
\hline $\begin{array}{l}\% \text { disabled } \\
\text { standard error }\left(\sigma_{\nu}\right) \\
\text { offer probability }\end{array}$ & $705.942(19.98)$ & $695.580(21.29)$ & $684.898(22.25)$ \\
\hline constant & $-2.197(2.80)$ & $-2.175(3.07)$ & $-1.43(1.83)$ \\
\hline \# of yrs in program & $-0.385(9.23)$ & $-0.367(9.01)$ & $-0.396(9.57)$ \\
\hline age $/ 5$ & $0.407(1.64)$ & $0.347(1.53)$ & $0.185(0.78)$ \\
\hline$(\operatorname{age} / 5)^{2}$ & $-0.039(2.50)$ & $-0.035(2.41)$ & $-0.026(1.72)$ \\
\hline $\log ($ age $)$ & & & \\
\hline work experience/5 & $-0.165(1.36)$ & $-0.101(0.93)$ & $-0.043(0.37)$ \\
\hline$(\text { work experience } / 5)^{2}$ & $0.026(2.03)$ & $0.019(1.63)$ & $0.014(1.15)$ \\
\hline $\log ($ work experience) & & & \\
\hline years of education & $0.023(1.73)$ & $0.023(1.85)$ & $0.016(1.19)$ \\
\hline $\begin{array}{l}\text { female } \\
\text { disutility of working }\end{array}$ & $-0.041(0.50)$ & $-0.085(1.14)$ & $-0.008(0.10)$ \\
\hline constant & $318.520(5.75)$ & $262.259(4.96)$ & $370.707(6.84)$ \\
\hline log likelihood (LL) & -3499.28 & - & -3490.42 \\
\hline
\end{tabular}

Table 13. Health variables in wage offer ( T-statistics in parenthesis). 


\subsection{Health variables in the job offer probability}

Next we include health variables in the offer probability rather than the wage offer equation (Tables 14 and 15). Regarding the wage offer distribution we still find that there is a strong pay off to education and that women earn about one standard deviation less then their male counterparts. When we look at the effect of the health variables on the job offer probability we do observe significant negative effects. When looking at the effect of overall health status we find that those who report a worse overall health, are also the ones that have a lower probability of being offered a job, conditional on all other variables. Furthermore, the disutility of working is reduced although it remains significant.

\begin{tabular}{|c|c|c|c|c|}
\hline wage offer & \multicolumn{2}{|c|}{ IV } & \multicolumn{2}{|c|}{ V } \\
\hline constant & 144.717 & $(0.16)$ & 131.625 & $(0.13)$ \\
\hline $\log$ (work experience) & 319.584 & $(2.59)$ & 341.719 & $(2.50)$ \\
\hline $\log ($ age $)$ & -20.640 & $(0.06)$ & -73.983 & $(0.20)$ \\
\hline years of education & 105.909 & $(9.02)$ & 114.854 & $(8.95)$ \\
\hline female & -654.764 & $(8.03)$ & -693.932 & $(7.68)$ \\
\hline standard error $\left(\sigma_{\nu}\right)$ & 633.885 & $(26.99)$ & 668.882 & $(24.20)$ \\
\hline \multicolumn{5}{|l|}{ offer probability } \\
\hline constant & 3.058 & $(4.11)$ & 3.188 & $(4.22)$ \\
\hline \# of yrs in prog & -0.347 & $(8.71)$ & -0.335 & $(8.52)$ \\
\hline $\log ($ age $)$ & -1.442 & $(5.45)$ & -1.489 & $(5.61)$ \\
\hline $\log$ (work experience) & 0.221 & $(2.07)$ & 0.235 & $(2.23)$ \\
\hline years of education & 0.019 & $(1.56)$ & 0.022 & $(1.91)$ \\
\hline female & -0.066 & $(0.95)$ & -0.098 & $(1.46)$ \\
\hline \multirow{8}{*}{$\begin{array}{l}\text { difficulties with: } \\
\text { - basic motion } \\
\text { - hand/finger } \\
\text { other then hand/finger } \\
\text { or basic motion } \\
\text { medium good health } \\
\text { medium bad health } \\
\text { bad health } \\
\text { disutility of working }\end{array}$} & & & & \\
\hline & -0.038 & $(2.07)$ & & \\
\hline & -0.217 & $(3.89)$ & & \\
\hline & -0.004 & $(0.44)$ & & \\
\hline & & & -0.010 & $(0.10)$ \\
\hline & & & -0.335 & $(3.43)$ \\
\hline & & & -0.530 & $(-5.16)$ \\
\hline & & & & \\
\hline constant & 249.797 & $(4.31)$ & 194.282 & $(3.44)$ \\
\hline log likelihood (LL) & -349 & & -349 & 74 \\
\hline
\end{tabular}

Table 14. Health variables in the job offer probability (T-statistics in parenthesis). 


\begin{tabular}{|c|c|c|c|c|}
\hline wage offer & \multicolumn{2}{|c|}{$\mathrm{VI}$} & \multicolumn{2}{|c|}{ VII } \\
\hline constant & 131.260 & $(0.12)$ & 131.253 & 0.13 \\
\hline $\log$ (work experience) & 344.299 & $(2.39)$ & 361.161 & 2.64 \\
\hline $\log ($ age $)$ & -65.835 & $(0.17)$ & -85.542 & 0.23 \\
\hline years of education & 11.975 & $(8.32)$ & 114.515 & 8.56 \\
\hline female & -693.871 & $(7.28)$ & -693.298 & 7.31 \\
\hline $\begin{array}{l}\text { standard error }\left(\sigma_{\nu}\right) \\
\text { offer probability }\end{array}$ & 685.123 & $(23.03)$ & 686.562 & 22.67 \\
\hline constant & 3.174 & $(4.11)$ & 3.691 & 4.44 \\
\hline \# of yrs in program & -0.331 & $(8.23)$ & -0.334 & 8.00 \\
\hline $\log ($ age $)$ & -1.478 & $(5.44)$ & -1.572 & 5.40 \\
\hline $\log$ (work experience) & 0.245 & $(2.27)$ & 0.242 & 2.11 \\
\hline years of education & 0.020 & (1.67) & 0.003 & 0.20 \\
\hline female & -0.062 & $(0.89)$ & -0.086 & 1.15 \\
\hline difficulties with: & & & & \\
\hline - basic motion & -0.021 & $(1.07)$ & -0.018 & 0.87 \\
\hline · hand/finger & -0.214 & $(3.78)$ & -0.189 & 3.19 \\
\hline $\begin{array}{l}\text { other then hand/finger } \\
\text { or basic motion }\end{array}$ & 0.006 & $(0.65)$ & 0.009 & 0.90 \\
\hline complaints expected to $\uparrow$ & & & -0.019 & 0.17 \\
\hline complaints expected to $\downarrow$ & & & 0.453 & 5.72 \\
\hline medium good health & 0.002 & $(0.02)$ & -0.099 & 0.91 \\
\hline medium bad health & -0.302 & $(2.90)$ & -0.358 & 3.19 \\
\hline $\begin{array}{l}\text { bad health } \\
\text { disutility of working }\end{array}$ & -0.489 & $(4.18)$ & -0.525 & 4.28 \\
\hline constant & 191.634 & $(3.33)$ & 272.265 & 4.93 \\
\hline log likelihood (LL) & 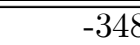 & & 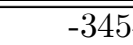 & \\
\hline
\end{tabular}

Table 15. Health variables in the job offer probability (T-statistics in parenthesis). 


\subsection{Health variables in the disutility of working}

In table 16 we explore a third option by including health variables in the disutility of work specification. Overall our other parameters are fairly robust. The observed pattern is one of increasing disutility of work the higher the percent disabled or the worse the overall reported health status reported is.

\begin{tabular}{|c|c|c|c|}
\hline wage offer & VIII & IX & $\mathrm{X}$ \\
\hline constant & $131.792(0.13)$ & $131.549(0.13)$ & $131.571(0.13)$ \\
\hline $\log$ (work experience) & $341.153(2.63)$ & $361.857(2.72)$ & $361.522(2.60)$ \\
\hline $\log ($ age $)$ & $-74.344(0.21)$ & $-86.135(0.24)$ & $-86.284(0.23)$ \\
\hline years of education & $114.306(8.99)$ & $113.670(8.66)$ & $113.015(8.56)$ \\
\hline female & $-693.690(7.78)$ & $-694.140(7.75)$ & $-694.061(7.50)$ \\
\hline standard error $\left(\sigma_{\nu}\right)$ & $659.722(25.26)$ & $668.309(24.56)$ & $685.284(23.81)$ \\
\hline \multicolumn{4}{|l|}{ offer probability } \\
\hline constant & $2.716(3.92)$ & $2.832(3.95)$ & $3.269(4.25)$ \\
\hline \# of yrs in program & $-0.357(9.64)$ & $-0.349(9.64)$ & $-0.363(9.42)$ \\
\hline $\log ($ age $)$ & $-1.394(5.47)$ & $-1.409(5.32)$ & $-1.492(5.37)$ \\
\hline $\log ($ work experience) & $0.184(1.79)$ & $0.207(1.93)$ & $0.207(1.87)$ \\
\hline years of education & $0.028(2.42)$ & $0.019(1.61)$ & $0.014(1.09)$ \\
\hline female & $-0.100(1.50)$ & $-0.063(0.94)$ & $-0.053(0.75)$ \\
\hline \multicolumn{4}{|l|}{ disutility of working } \\
\hline \multirow{8}{*}{$\begin{array}{l}\text { difficulties with: } \\
\text { - basic motion } \\
\text {. hand/finger } \\
\text { other then hand/finger } \\
\text { or basic motion } \\
\text { medium good health } \\
\text { medium bad health } \\
\text { bad health } \\
\% \text { disabled }\end{array}$} & & & \\
\hline & & $83.281(2.96)$ & $66.100(2.61)$ \\
\hline & & $283.223(3.61)$ & $258.732(3.44)$ \\
\hline & & $-3.134(0.23)$ & $-19.581(1.50)$ \\
\hline & & & $81.245(0.83)$ \\
\hline & & & $283.947(3.39)$ \\
\hline & & & $497.520(3.97)$ \\
\hline & $3.033(5.96)$ & & \\
\hline log likelihood (LL) & -3503.77 & -3494.67 & -3487.78 \\
\hline
\end{tabular}

Table 16. Health variables in the disutility of working (T-statistics in parenthesis).

\subsection{Health variables in both the job offer probability and wage offer}

Finally, when we include the health variables in both the wage and job offer probability equations (Table 17), the disutility of working disappears and we end up with our specification that will be the basis for analyzing the effects of our proposed changes to the disability program. 


\begin{tabular}{|c|c|c|c|}
\hline & $\mathrm{O}$ & & means \\
\hline constant & 441.188 & $(0.41)$ & \\
\hline log(work experience) & 310.571 & $(2.21)$ & 2.926 \\
\hline $\log ($ age $)$ & -70.657 & $(0.18)$ & 3.704 \\
\hline years of education & 98.715 & $(7.09)$ & 11.376 \\
\hline female & -631.343 & $(6.95)$ & 0.460 \\
\hline difficulties with: & & & \\
\hline basic motion & 5.477 & $(0.18)$ & 2.743 \\
\hline hand/finger & 16.591 & $(0.15)$ & 0.364 \\
\hline $\begin{array}{l}\text { other then hand/finger } \\
\text { or basic motion }\end{array}$ & -16.437 & $(1.25)$ & 8.005 \\
\hline medium good health & 53.352 & $(0.47)$ & 0.296 \\
\hline medium bad health & 23.965 & $(0.18)$ & 0.293 \\
\hline bad health & 13.537 & $(0.09)$ & 0.307 \\
\hline standard error $\left(\sigma_{\nu}\right)$ & 656.140 & $(23.94)$ & \\
\hline constant & 2.306 & $(3.47)$ & \\
\hline \# of yrs in program & -0.273 & $(7.41)$ & \\
\hline $\log ($ age $)$ & -1.284 & $(5.49)$ & 3.704 \\
\hline $\log$ (work experience) & 0.242 & $(2.67)$ & 2.926 \\
\hline years of education & 0.016 & $(1.44)$ & 11.376 \\
\hline female & -0.136 & $(2.21)$ & 0.460 \\
\hline difficulties with: & & & \\
\hline basic motion & -0.015 & $(0.82)$ & 2.743 \\
\hline . hand/finger & -0.168 & $(3.13)$ & 0.364 \\
\hline $\begin{array}{l}\text { other then hand/finger } \\
\text { or basic motion }\end{array}$ & 0.008 & $(0.93)$ & 8.005 \\
\hline complaints expected to $\uparrow$ & -0.030 & $(0.30)$ & 0.137 \\
\hline complaints expected to $\downarrow$ & 0.407 & $(6.22)$ & 0.253 \\
\hline medium good health & -0.078 & $(0.85)$ & 0.296 \\
\hline medium bad health & -0.308 & $(3.20)$ & 0.293 \\
\hline bad health & -0.476 & $(4.47)$ & 0.307 \\
\hline constant & 6.872 & $(0.07)$ & \\
\hline log likelihood (LL) & -3445.56 & & \\
\hline
\end{tabular}

Table 17. Health variables in both the wage offer and the job offer probability ( T-statistics in parenthesis). 


\subsection{Assessment of model fit}

In order to get an insight in how far our model is able to capture the observed reality we computed the predicted wage for each individual based on the parameter estimates from table 17 . When we plot each pair of predicted offered wage and the last earned wage we find that our predicted wages mimic the individual's last earned wages (figure 5). The straight line represents the 45 degree line.

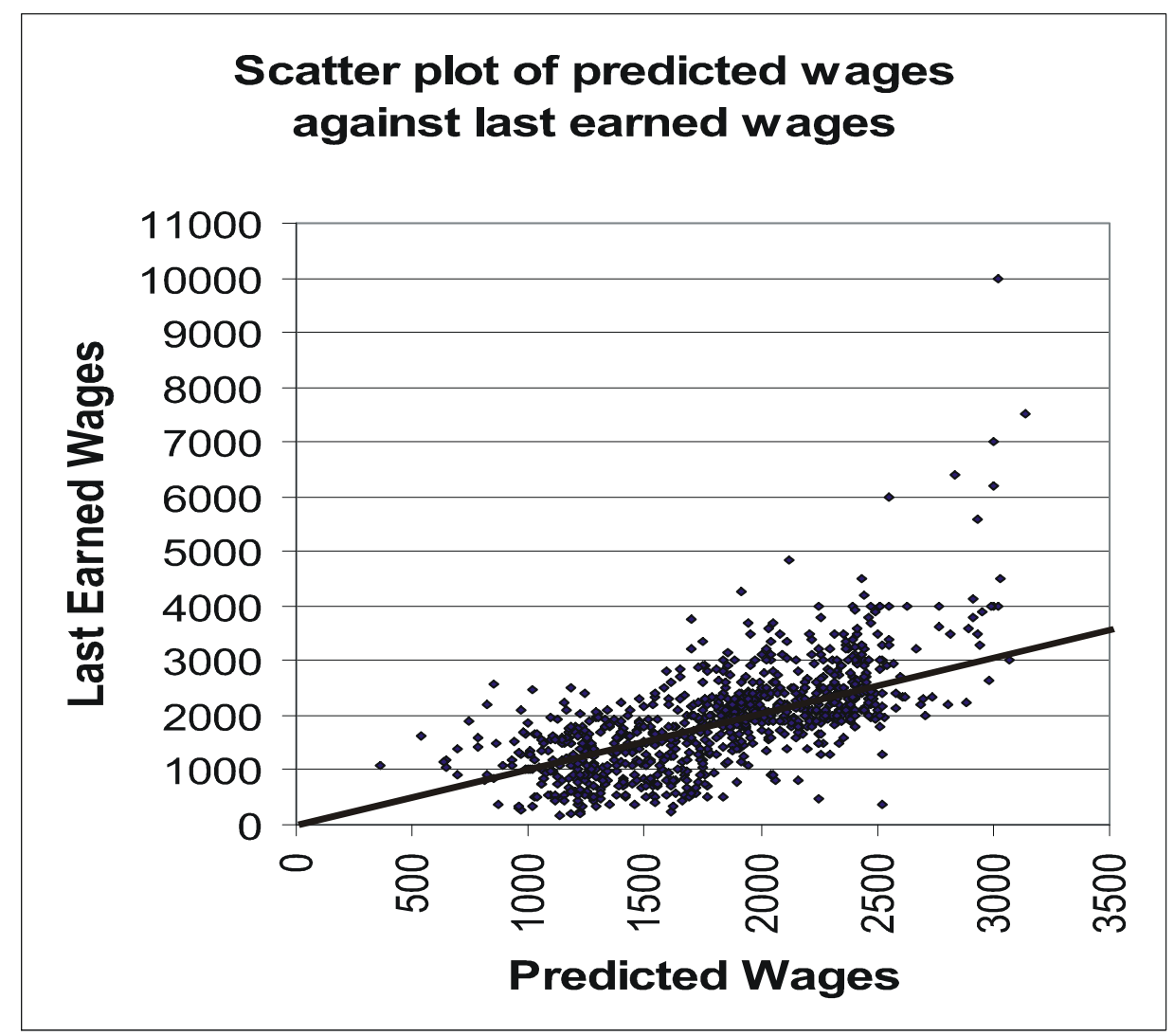

Figure 5. Scatter plot of predicted wages against last earned wages.

Although it is interesting to compare these predicted offered wages to the last earned wages, the accurate assessment of model fit is obtained by comparing the predicted offered wages to the actual accepted wages for those individuals who resumed work. This is done in figure 6 . As is clear from the scatterplot, the model does quite a decent job in predicting the accepted wages, although this does not hold for the extremely low or high end wages. If the model would 


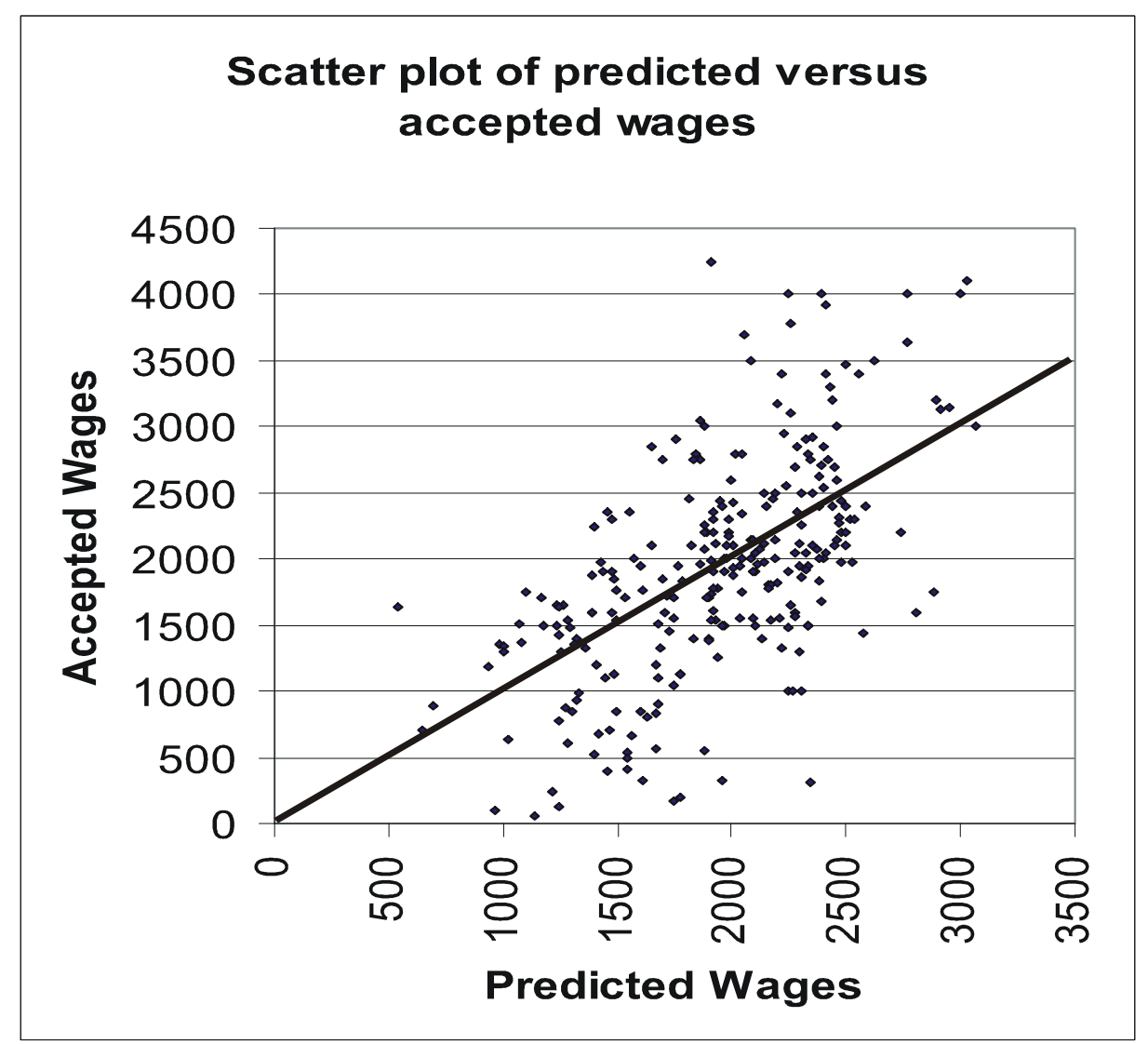

Figure 6. Scatter plot of predicted vs. actual accepted wages.

Besides the graphical assessment of the ability of the model to predict the accepted wages, we can also compute the standard measure of model fit, the $\mathrm{R}^{2}$. Using only those individuals who return to work, we find an $\mathrm{R}^{2}$ of 0.353 . When we calculate the $\mathrm{R}^{2}$ for the different specifications in tables 13 through 17 we find only slightly lower scores, ranging from 0.318 through 0.339 .

Another assessment of the performance of the model is to compare the empirically observed hazard with the one implied by the model. We do so by comparing the actual fraction of people returning to work in any given period by their average predicted probability of returning to work in that period based on the parameter estimates in table 17. For each individual we can compute this probability of returning to work in any given period since we can integrate the wage offer distribution over the applicable, individual specific, and time 
varying, set of acceptable wages we compute when solving the model. This will give us the probability of accepting an offer, conditional on receiving an offer. When we then multiply this by the probability of receiving an offer we obtain the model implied hazard, i.e. the probability of returning to work conditional on not having done so prior to this point.

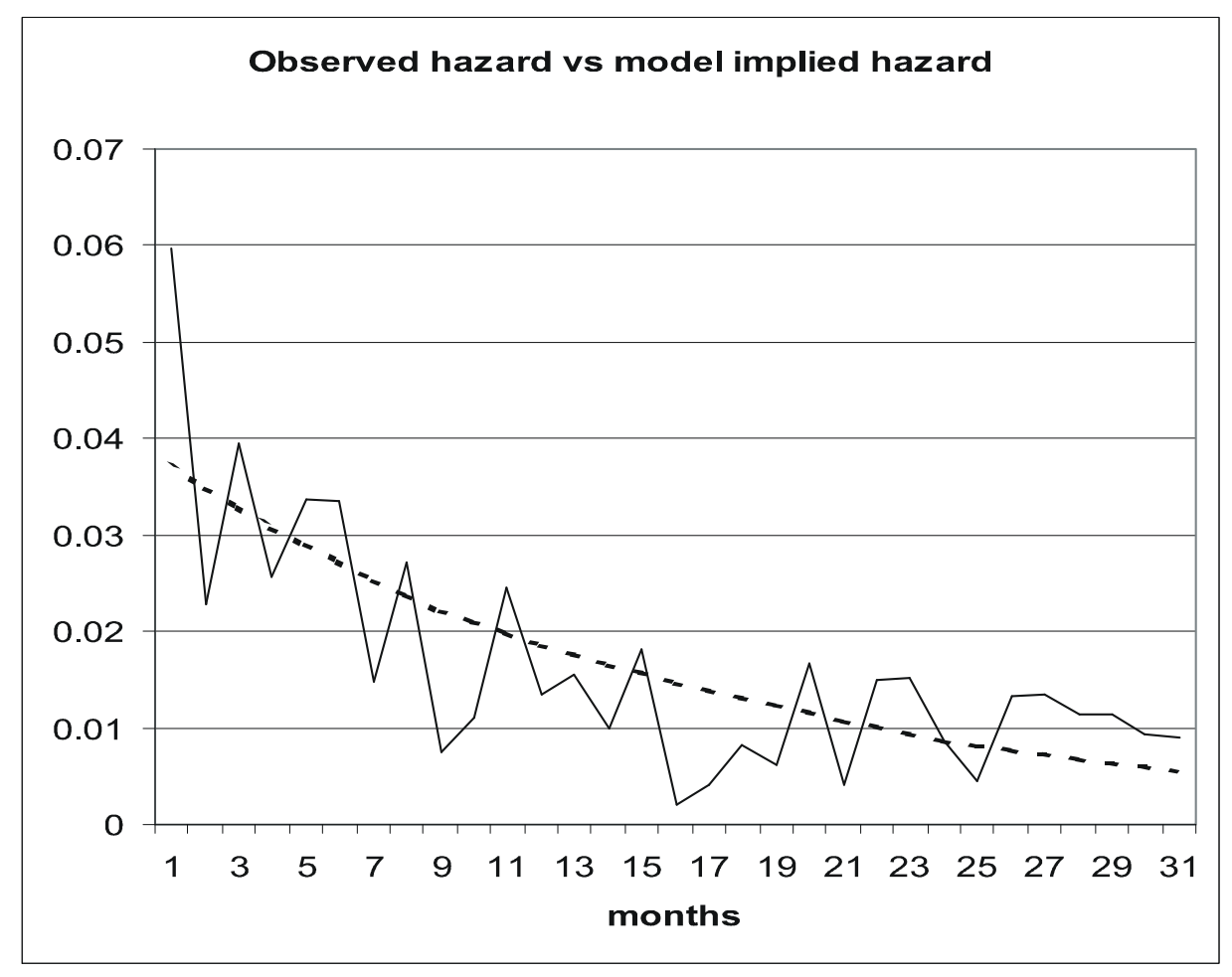

Figure 7. Model implied vs. actual observed hazard rates.

Contrary to a classic job search model we do not have a reservation wage that determines if a wage offer will be accepted or rejected. Instead, we have a set of acceptable wages that can be expressed as eight or less disjoint intervals. For each period, and for each individual, we can compute the expected accepted wage by integrating the wage offer distribution over the applicable set of acceptable wages. Figure 8 displays the kernel density estimates of the distribution of expected accepted wages at three different points in time: at the start of enrollment in the disability program, one year after entering the program and finally $2 \frac{1}{2}$ years after entering the program. Similar to observing reservation wages decline over time, we observe the distribution of expected accepted wages shifting to the left. 
Kernel Densities of the Expected

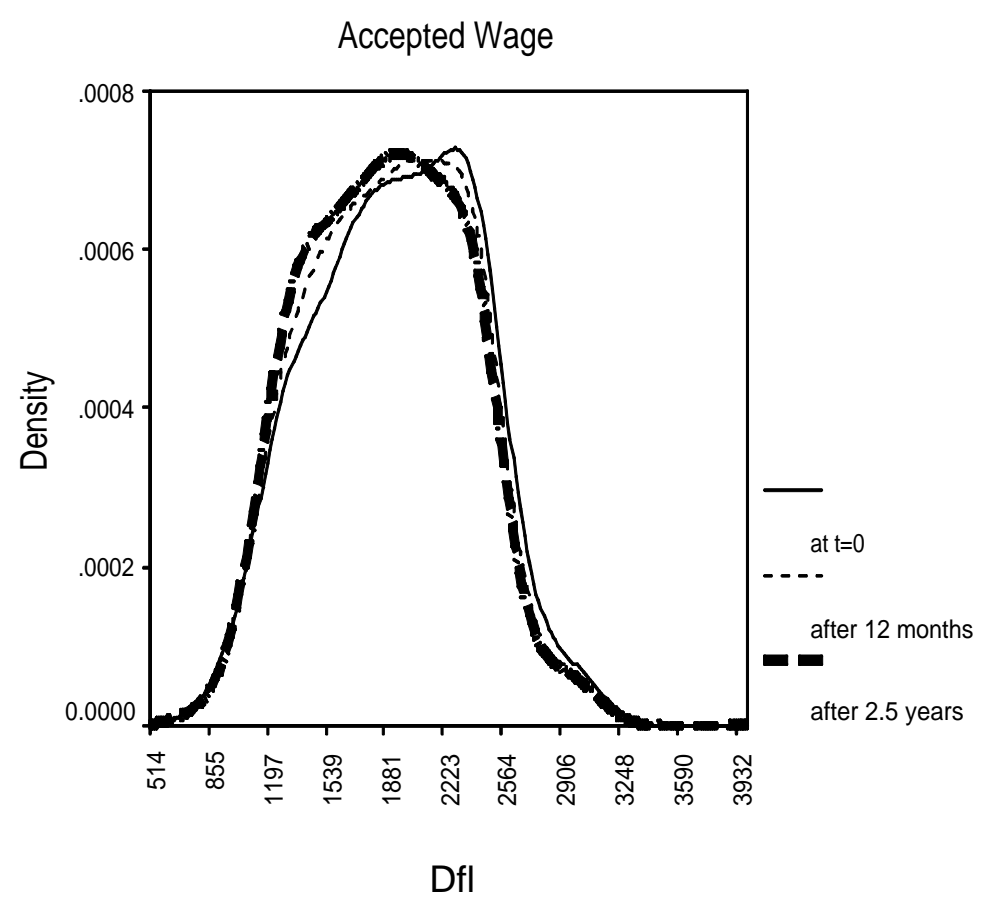

Figure 8. Kernel density estimates of the expected accepted wage. 


\section{Evaluating modifications to the disability pro- gram}

One of the advantages of the behavioral model is that it allows us to analyze what would happen if we were to make any changes to the disability program. We limit ourselves to four scenarios, being

I: Reducing the benefits when not employed by $25 \%$

II: Increasing the benefits when not employed by $25 \%$

III: Limiting the duration of the high unemployment benefits to 6 months

IV: Eliminating the disability program by replacing it with the unemployment program

We make the distinction between increasing and reducing benefits since they do not have equal impacts, as we will see later. Figure 9 plots the average probability of accepting an offer, conditional on receiving an offer, over time and for each of the four scenarios. For each individual we can compute his probability of accepting an offer by integrating the wage offer distribution over the applicable, individual specific, and time varying, set of acceptable wages. 


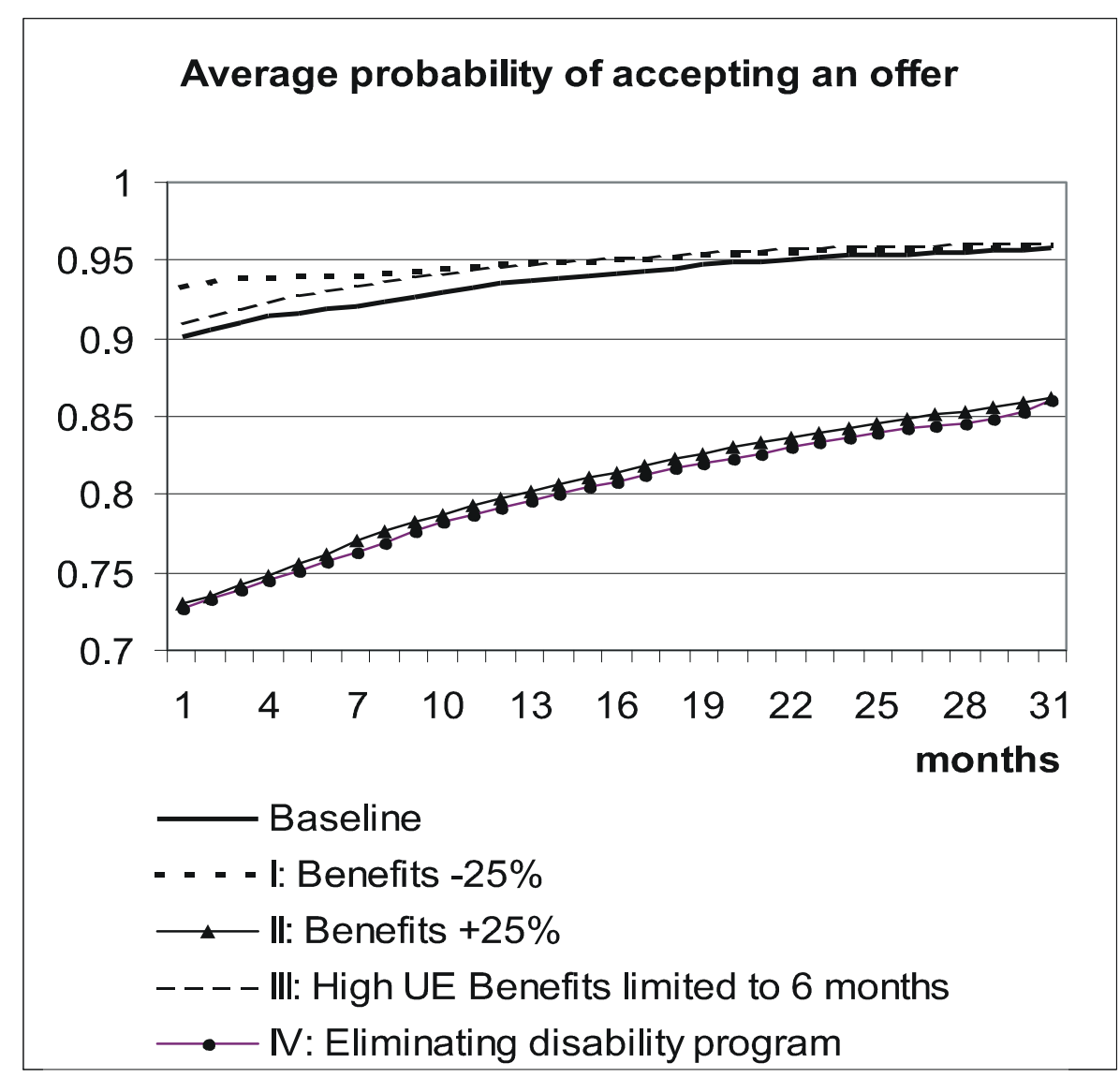

Figure 9. Average job acceptance probabilities.

The solid line is the average probability of accepting an offer implied by the estimated coefficients in table 17 and serves as a point of reference. The average acceptance probability is high, around $90 \%$ at the start of enrollment, and increases to around $95 \%$ over time. This increase is a different representation of the same dynamics as was displayed in figure 8 by the shift in the distribution of expected accepted wages over time. Eliminating the disability program (IV) will lower the average probability of accepting an offer. The reason why the acceptance probability declines when we eliminate the disability program can be best explained by using the figures 3 and 4 . As a reminder, the fat jagged line represents the total income from work and disability benefits at different wage levels. The utility of not working can be represented by a horizontal line in the same graph. We accept those wages for which the fat jagged line lies above that level. As a result, when we eliminate the disability program altogether, we 
also eliminate the attractiveness of low paying jobs because the fat jagged line would collapse to the 45 degree line. The effect of benefits on the work decision is not easily captured in one parameter. When we increase the benefits from disability and unemployment when not working by $25 \%$ (II), we reduce the average probability of accepting an offer. Conversely, a reduction of $25 \%$ (I) leads to an increase in the average probability, albeit this effect is much weaker. This is due to the fact that the acceptance probability is already high as it is. With the job offer probability unaffected, the observed responses to changes in the level of benefits imply that higher benefits are associated with lower hazard rates. Combining the effects of the proposed changes to the disability program on the probability of accepting an offer with the probability of receiving an offer, we can compare the implied hazard functions resulting from these changes. This is done in figure 10. We find a negligible effect of limiting the duration of the high unemployment benefits to six months. When we reduce the benefits we do increase the hazard rate but the increase only seems to be of importance in the first year or so. This holds much less for the other changes, the increase in benefits and the elimination of the disability program. Both changes lower the hazard rate considerably and approximately in an equal fashion. However, the underlying mechanics are very different. In terms of the equations to solve the model, the increase in the benefits increases the right-hand-side of the inequality. This, in terms of figures 3 and 4 , raises the imaginary horizontal line, thereby reducing the attractiveness of all jobs and contracting the intervals of acceptable wages across the board. In contrast, eliminating the disability program collapses the jagged total income line in figures 3 and 4 to the 45 degree line, thereby eliminating only the attractiveness of the relatively low paying jobs. 


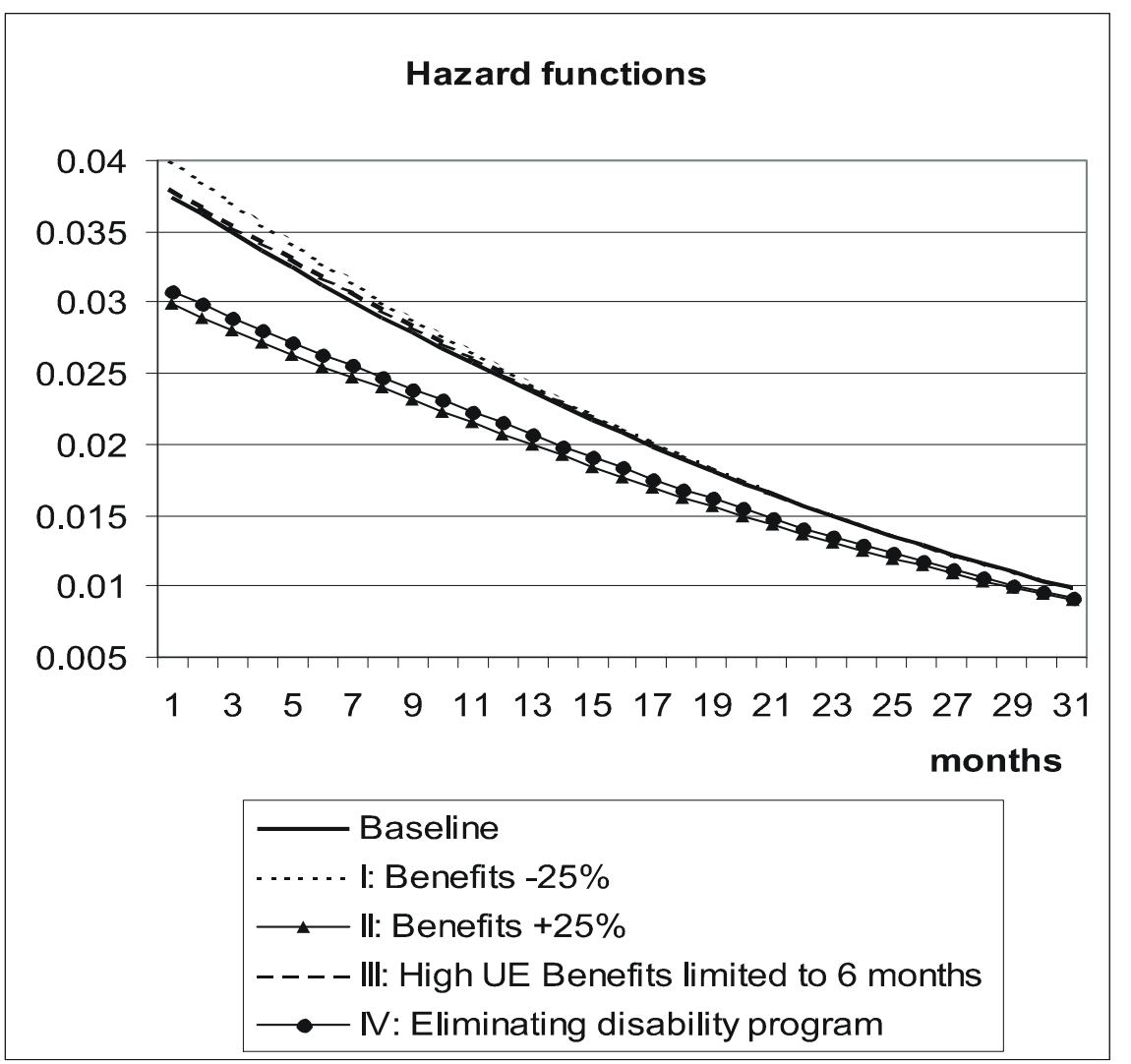

Figure 10. Model implied hazard rates over time.

When proposing policies to reduce the rolls of the disability program, those who are in the program will pay a price. One element of this price is captured by the accepted wages. Lowering benefits will result in more people returning to work, and faster, but they do so by accepting lower wages. When we calculate the expected accepted wage for each individual at each period and then take the average over all individuals for each period, we obtain the mean expected accepted wage profiles over time, for each of our four alternatives. We find that reducing the benefits by $25 \%$ leads to a reduction in the mean expected accepted wage of roughly Dfl. 40 , or about $2 \%$, at the start of enrollment. Over time, the profile of the mean expected accepted wage approaches the original benchmark profile. On the other hand, eliminating the disability program, or increasing the benefits by $25 \%$, leads to an increase in the mean expected accepted wage of roughly Dfl. 175 , or about $9 \%$, at the start of enrollment in the program. 


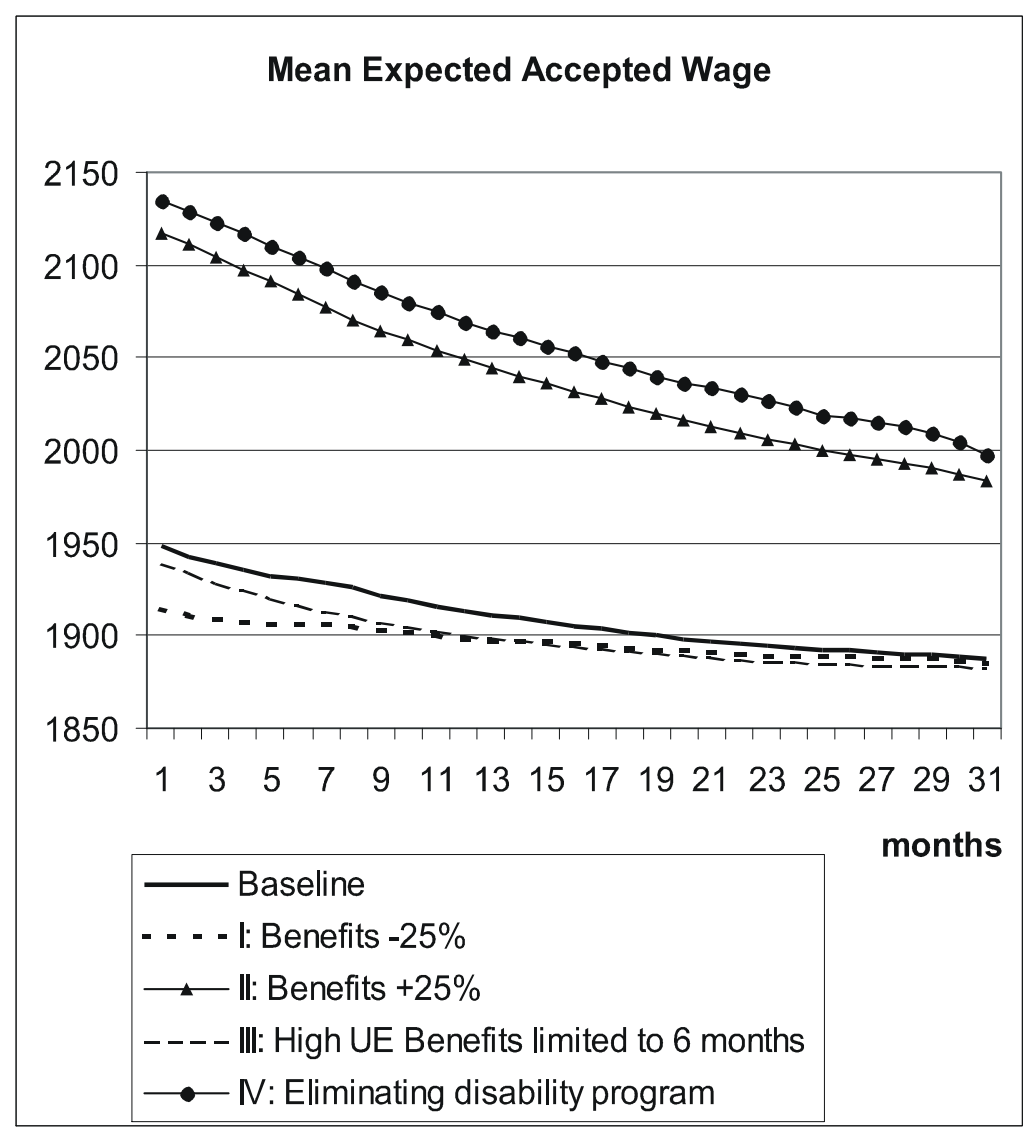

Figure 11. Model implied mean expected accepted wages. 


\section{Concluding remarks}

Perhaps surprisingly, the Dutch disability program is quite dynamic. Approximately one third of the people entering the program return to work at some point during the time span of the data (Nov.1991 - May 1994). One thing to keep in mind is that disability only applies to a loss in earning capacity and is different from the common everyday meaning. This leads to people entering the disability program who are still very much capable of doing some type of work. It is no surprise then to see people actually returning to work. Overall we find that health status variables do not play a significant role in the wage offer, but they do matter for the disutility of working and the probability of obtaining an offer. Unfortunately, our model can not distinguish between a reduction in the job offer probability due to a reluctance of employers to hire individuals with unfavorable health characteristics and a reduction due to a lower search intensity of people with unfavorable health characteristics. We find that worse overall health is associated with smaller probabilities of returning to work and that the reverse holds for increasing levels of education and work experience. Eliminating the disability program by transferring everyone to the unemployment program results in fewer people returning to work. This is due to the fact that the disability program allows for a supplemental benefit on top of the earnings from wages in case this wage is sufficiently low. The higher the level of disability, the more low paying jobs are desirable. When we eliminate the disability program, we also eliminate the attractiveness of these low paying jobs. Increasing the benefits when not working by $25 \%$ has a similar effect on the labor supply of people enrolled in the disability program. This is not caused by the loss of the wage subsidy for low paying jobs as was the case with the elimination of the disability program, but due to an increase in the value of staying at home. Reducing the benefits increases the number of people returning to work by increasing their set of acceptable wages. We find that a reduction in the benefits of $25 \%$ leads to a reduction of $2 \%$ in the mean expected accepted wage at the start of enrollment in the disability program. In contrast, an increase in the benefits level of $25 \%$ leads to a $9 \%$ increase of the mean expected accepted wage. In summary, reducing benefits as a measure to increase the incidence of people returning to work is not very effective since the probability of accepting a job is already very high. The opposite, increasing the benefits, will lead to a sharp drop in the number of people returning to work, as will an elimination of the disability program. Policies designed to increase the number of people returning to work should therefore be aimed at increasing the probability of obtaining an offer, rather than look to increase the acceptance probability. 


\section{Appendix}

The set of acceptable wages in period t can always be expressed as a collection of eight or less disjoint intervals. To do so let $\mathrm{RHS}_{t}$ be the right-hand side in the work decision equation for period t. Again, $l_{j}$ is the fraction of the last earned wage (lew) one gets depending on which of the eight different disability brackets one is in (Table 10).

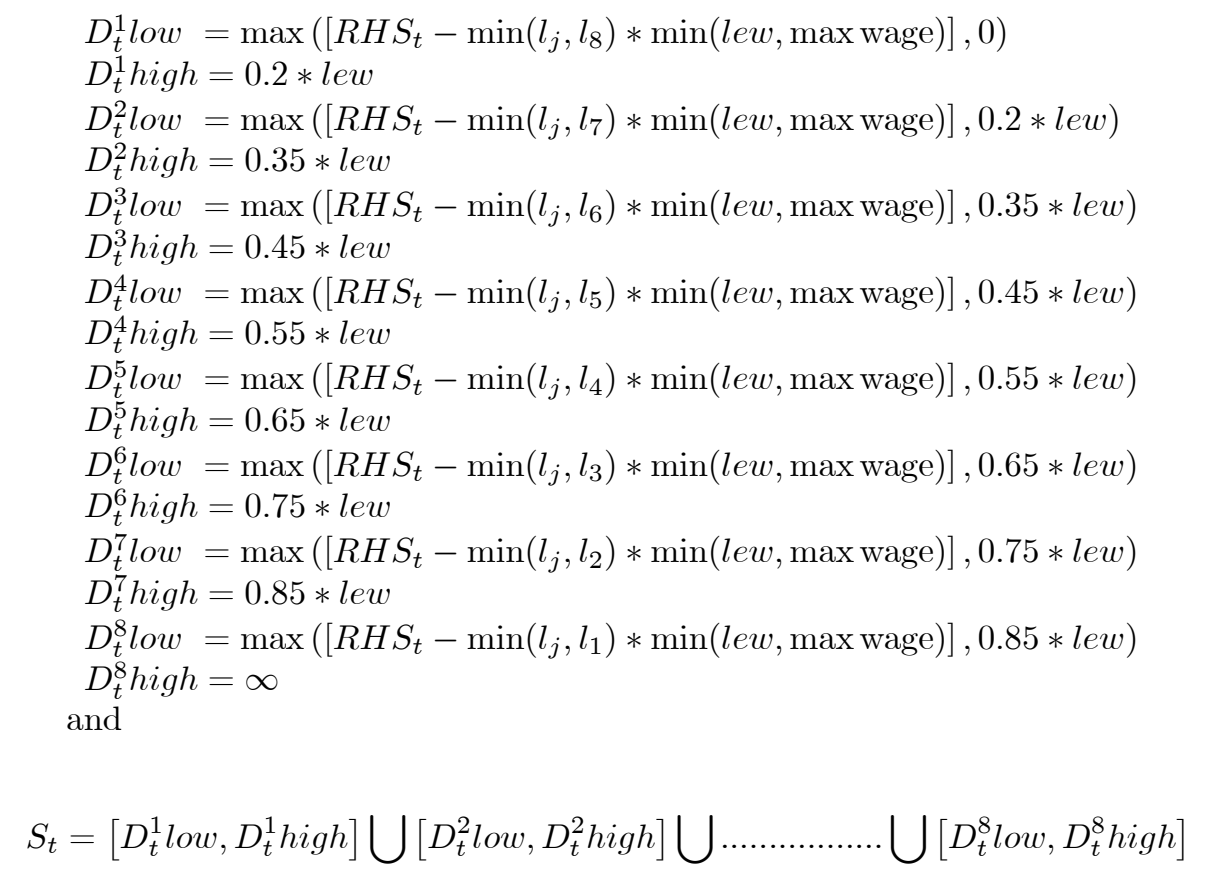




\section{Bibliography}

Aarts, L.J.M. and de Jong, P.R., 1992, Economic Aspects of Disability Behavior, Contributions to Economic Analysis, vol. 207. North-Holland, Amsterdam, The Netherlands.

Aarts, L.J.M., Burkhauser, R.V., de Jong, P.R., Eds., 1996, Curing the Dutch disease: An international perspective on disability policy reform, International Studies on Social Security, vol. 1. Aldershot, U.K. and Brookfield, Vt.: Ashgate, Avebury.

Emanuel, H., Halberstadt, V. and Petersen, C., 1984, Disability Policy in the Netherlands, in Haveman, R.H., Halberstadt, V. and Burkhauser, R.V. (eds.), Public Policy toward Disabled Workers, Cornell University Press, Ithaca, NY, pp.399-443.

Gelauff, G.M.M., Graafland, J.J., 1994, Modelling welfare state reform, Contributions to Economic Analysis, vol. 225. North-Holland, Amsterdam, The Netherlands.

Hassink, W.H., Van Ours, J. and Ridder, G., 1997, Dismissal through disability, De Economist, Vol. 145.

Haveman, R., de Jong, P. and Wolfe, B., 1991, Disability transfers and the work decision of older men, The Quarterly Journal of Economics, Vol.106, No.3, 939-949.

Kapteyn, A. and de Vos, K., 1997, Social Security and Retirement in the Netherlands, NBER Working Paper 6135

Kerkhofs, M., Lindeboom, M. and Theeuwes, J., 1999, Retirement, financial incentives and health, Labour Economics, Vol. 6, No.2, 203-227

Mooij, R.A. de, 1999, Disability Benefits and Hidden Unemployment in The Netherlands, Journal of Policy modeling, Vol.21, No.6, 695-713.

Parsons, Donald O., 1980, The decline in male labor force participation, Journal of Political Economy, Vol.88, No.1, 117-134.

Spijkerboer, P.M. and van der Zee, H., 1996, Kroniek van de sociale verzekeringen 1996 (in Dutch), College van toezicht sociale verzekeringen (Ctsv), ISSN 0922-856X.

Stelt, H.J. van der and Bruinsma, H., 1997, De positie van de WAO-client, PES3 [ computer-file], Amsterdam, Steinmetzarchief (Steinmetzarchiefnummer $\mathrm{P} 1261)$ 


\section{IZA Discussion Papers}

\section{No Author(s)}

181

E. Wasmer

Y. Zenou

182 M. Fertig

C. M. Schmidt

183 M. Fertig

C. M. Schmidt

184 M. Corak

B. Gustafsson

T. Österberg

185 H. Bonin

K. F. Zimmermann

186

C. Dustmann

187
T. K. Bauer
M. Lofstrom
K. F. Zimmermann

188
A. Kapteyn
A. S. Kalwij
A. Zaidi

189

W. Arulampalam

190

C. Dustmann

I. Preston

191

192

G. C. Giannelli

C. Monfardini

193 A. Kunze

F. Pastore

G. Brunello

F. Büchel

A. Mertens

Titel

Area

Date

Space, Search and Efficiency

2

$8 / 00$

Discretionary Measures of Active Labor Market Policy: The German Employment Promotion Reform in Perspective

Aggregate-Level Migration Studies as a Tool for 1 Forecasting Future Migration Streams

Intergenerational Influences on the Receipt of 3 Unemployment Insurance in Canada and Sweden

The Post-Unification German Labor Market

4

$8 / 00$

Temporary Migration and Economic Assimilation

$8 / 00$

Immigration Policy, Assimilation of Immigrants and Natives' Sentiments towards Immigrants: Evidence from 12 OECD-Countries

The Myth of Worksharing

5

$8 / 00$

Is Unemployment Really Scarring? Effects of

3

$8 / 00$

Unemployment Experiences on Wages

Racial and Economic Factors in Attitudes to

Immigration

$8 / 00$

Joint Decisions on Household Membership and Human Capital Accumulation of Youths: The role of expected earnings and local markets

$8 / 00$

Absolute Risk Aversion and the Returns to

5

$8 / 00$ Education

The Determination of Wages and the Gender Wage Gap: A Survey

Restructuring in Poland

Overeducation, Undereducation, and the Theory of Career Mobility 
198 M. Kreyenfeld

A Forgotten Issue: Distributional Effects of Day 
212 X. Gong

A. van Soest

P. Zhang

213 X. Gong

A. van Soest

E. Villagomez

214 X. Gong

A. van Soest

215 J. Ermisch

M. Francesconi

216 F. Büchel

217

J. Hansen

R. Wahlberg

218 C. Dustmann

A. van Soest

219 F. Kramarz

T. Philippon

220 W. A. Cornelius

E. A. Marcelli

221

C. Grund

222 W.P.M. Vijverberg

223 M. Rosholm

M. Svarer

J. Schwarze

225

L. Modesto

J. P. Thomas
Sexual Bias and Household Consumption: A

Mobility in the Urban Labor Market: A Panel Data 1

The Effect of Parents' Employment on Children's

The Effects of Overeducation on Productivity in Variables

The Impact of Differential Payroll Tax Subsidies on 5 Minimum Wage Employment United States: New Evidence from California and Mexico

Wages as Risk Compensation in Germany 

former Soviet Union to Israel: Who is coming when?

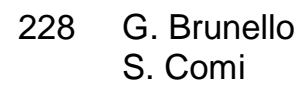

C. Lucifora

229 R. Coimbra

T. Lloyd-Braga

L. Modesto

230 L. Modesto

231

G. Saint-Paul

232

E. Bardasi

M. Francesconi

233

C. Dustmann

C. M. Schmidt

234

R. Rotte

M. Steininger

235

W. Schnedler

236
R. Hujer
M. Caliendo

237 S. Klasen

I. Woolard

238 R. Euwals

A. Börsch-Supan

A. Eymann

239 F. Andersson

K. A. Konrad

240

W. Koeniger
The College Wage Gap in 10 European and Earnings: An Empirical Study for Portugal Wahlerfolge in Deutschland: Das Beispiel der Europawahlen 1994 und 1999

Who gets the Reward? An Empirical Exploration of Bonus Pay and Task Characteristics

Evaluation of Active Labour Market Policy: 

Soviet Union: A Study of the Suicide Epidemic in the 1990s

244 S. M. Fuess, Jr. M. Millea

T. J. Hatton

J. G. Williamson

251

R. Yemtsov

252

R. Yemtsov

254 H. Gersbach

A. Schniewind

255 H. Gersbach

A. Schniewind

T. Boeri

H. Brücker

Pay and Productivity in a Corporatist Economy: 
258 M. Rosholm

The Times They Are A-Changin':

K. Scott

Organizational Change and Immigrant

L. Husted

Employment Opportunities in Scandinavia 